\title{
Bifurcation and Upwelling of the Equatorial Undercurrent West of the Galápagos Archipelago
}

\author{
JULIE JAKOBOSKI $^{\mathrm{a}}$ \\ MIT-WHOI Joint Program in Oceanography, Cambridge, Massachusetts \\ ROBERT E. TODD AND W. BRECHNER OWENS \\ Woods Hole Oceanographic Institution, Woods Hole, Massachusetts \\ KRISTOPHER B. KARNAUSKAS \\ University of Colorado Boulder, Boulder, Colorado \\ DANIEL L. RUDNICK \\ Scripps Institution of Oceanography, University of California, San Diego, La Jolla, California
}

(Manuscript received 7 May 2019, in final form 18 January 2020)

\begin{abstract}
The Equatorial Undercurrent (EUC) encounters the Galápagos Archipelago on the equator as it flows eastward across the Pacific. The impact of the Galápagos Archipelago on the EUC in the eastern equatorial Pacific remains largely unknown. In this study, the path of the EUC as it reaches the Galápagos Archipelago is measured directly using high-resolution observations obtained by autonomous underwater gliders. Gliders were deployed along three lines that define a closed region with the Galápagos Archipelago as the eastern boundary and $93^{\circ} \mathrm{W}$ from $2^{\circ} \mathrm{S}$ to $2^{\circ} \mathrm{N}$ as the western boundary. Twelve transects were simultaneously occupied along the three lines during 52 days in April-May 2016. Analysis of individual glider transects and average sections along each line show that the EUC splits around the Galápagos Archipelago. Velocity normal to the transects is used to estimate net horizontal volume transport into the volume. Downward integration of the net horizontal transport profile provides an estimate of the time- and areal-averaged vertical velocity profile over the 52-day time period. Local maxima in vertical velocity occur at depths of 25 and $280 \mathrm{~m}$ with magnitudes of $(1.7 \pm 0.6) \times 10^{-5} \mathrm{~m} \mathrm{~s}^{-1}$ and $(8.0 \pm 1.6) \times 10^{-5} \mathrm{~m} \mathrm{~s}^{-1}$, respectively. Volume transport as a function of salinity indicates that water crossing $93^{\circ} \mathrm{W}$ south (north) of $0.4^{\circ} \mathrm{S}$ tends to flow around the south (north) side of the Galápagos Archipelago. Comparisons are made between previous observational and modeling studies with differences attributed to effects of the strong 2015/16 El Niño event, the annual cycle of local winds, and varying longitudes between studies of the equatorial Pacific.
\end{abstract}

\section{Introduction}

The Galápagos Archipelago lies on the equator in the path of the eastward flowing Pacific Equatorial Undercurrent (EUC). The Galápagos Cold Pool (GCP) is a region of nutrient-rich, anomalously cool sea surface temperature (SST; Fig. 1) just west of the Galápagos

\footnotetext{
${ }^{\text {a }}$ Current affiliation: MetOcean Solutions, Raglan, New Zealand.
}

Corresponding author: Julie Jakoboski, jjakobos@alum.mit.edu
Archipelago that is characterized by wind- and currentdriven upwelling (Palacios 2004; Sweet et al. 2007). The GCP spans roughly the meridional extent of the Galápagos Archipelago and extends $300-500 \mathrm{~km}$ westward from Isla Isabela at $91^{\circ} \mathrm{W}$ (Houvenaghel 1978). Sources of upwelling associated with the GCP and possible connections to the EUC are not well understood.

Three distinct processes can cause upwelling in the vicinity of the Galápagos Archipelago. Westward trade winds (Fig. 2) drive horizontally divergent surface flow in two ways: 1) Ekman divergence due to the change in sign of the Coriolis parameter at the equator; and 
(a)

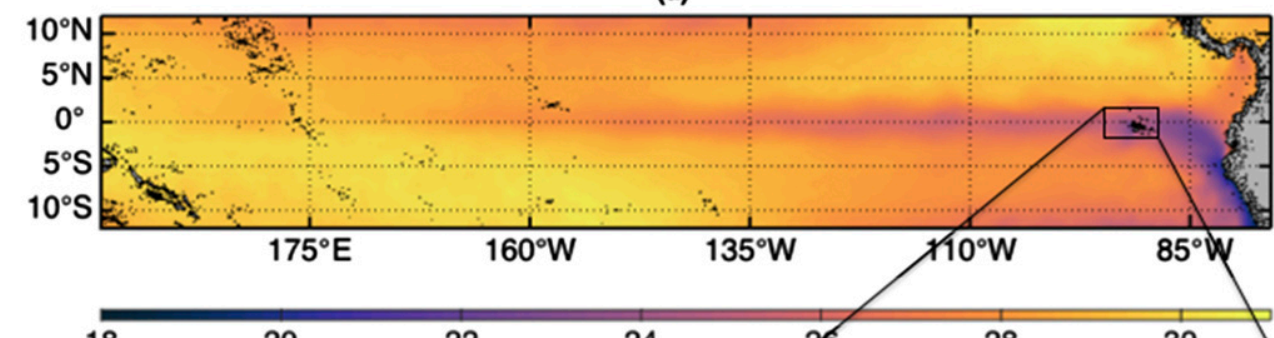

$18 \quad 20$

22

Temperature $\left(C^{26}\right)^{26}$

(b)
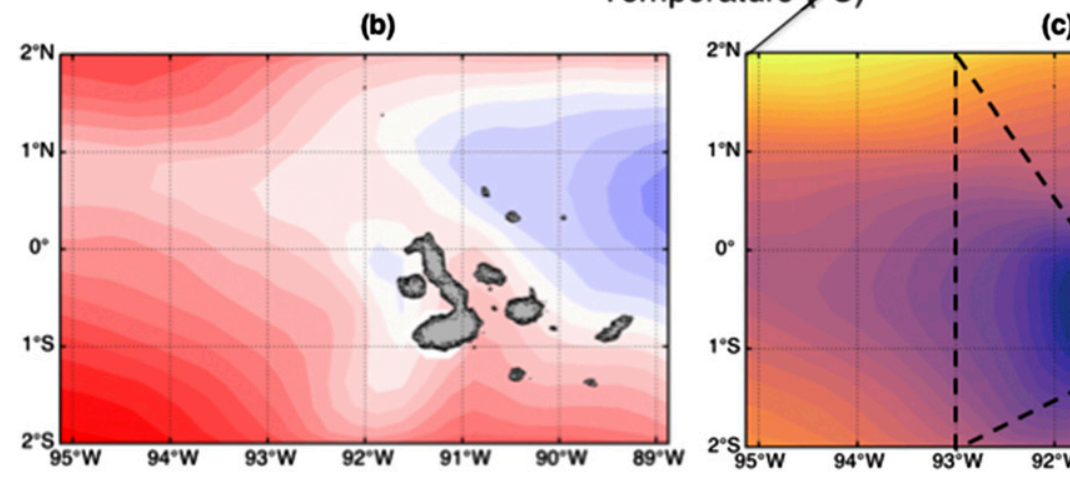

(c)

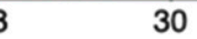

(c)
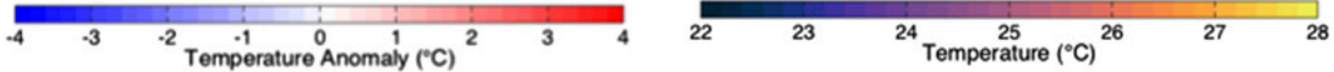

FIG. 1. (a) SST in the equatorial Pacific during 6 Apr-31 May 2016 with (c) the region around the Galápagos Archipelago enlarged to show the GCP. (b) SST anomalies during April-May 2016 relative to the 2004-16 climatology. Daily SST data are from the Group for High Resolution Sea Surface Temperature (GHRSST) provided with $1 / 4^{\circ} \times 1 / 4^{\circ}$ horizontal resolution (Reynolds et al. 2007; National Centers for Environmental Information 2016). Approximate ROGER glider transects are shown with dashed black lines (detailed transects are shown in Fig. 3).

2) downwind transport in the lee of the islands, which we refer to as "wind-driven coastal upwelling" despite differences from Ekman-driven coastal upwelling away from the equator. The third process can occur when a subsurface current encounters a sloping bottom or coast, which we will call "topographic upwelling." The observations of Houvenaghel (1978) showed that upwelling associated with the GCP continues even when winds are light and variable, suggesting that topographic upwelling of the EUC as it reaches the Galápagos Archipelago plays a primary role in maintaining the GCP. Liu et al. (2014) predicted the occurrence of both wind-driven and topographic upwelling of the EUC at the Galápagos Archipelago. Karnauskas et al. (2007) show that the GCP emerges without wind-topography interactions using a regional ocean model, indicating the importance of topographic upwelling.

Previously, equatorial upwelling and its connection to the EUC were examined using a box model from $170^{\circ} \mathrm{E}$ to $100^{\circ} \mathrm{W}$ by Wyrtki (1981) and using mooring observations at $140^{\circ} \mathrm{W}$ (Weisberg and Qiao 2000) and $170^{\circ}-95^{\circ} \mathrm{W}$ (Johnson et al. 2001). Vertical velocity profiles from
Weisberg and Qiao (2000) and Johnson et al. (2001) show similar shape with upwelling (positive vertical velocity) above $150-\mathrm{m}$ depth that is significantly different from zero above $50 \mathrm{~m}$. However, it is expected that upwelling just west of Galápagos Archipelago differs from general equatorial Pacific upwelling due to the presence of the archipelago, as indicated by the presence of the GCP.

The EUC is a relatively high velocity $\left(\sim 1 \mathrm{~m} \mathrm{~s}^{-1}\right)$, subsurface, coherent flow moving eastward along the equator at the depth of the thermocline. It was first documented by Cromwell et al. (1954) using taut-wire buoy observations. EUC dynamics can be described by a model driven by a depth-integrated zonal pressure gradient set up by an easterly wind stress (e.g., Charney 1959; Charney and Spiegel 1971; Pedlosky 1987; Johnson and Luther 1994; Qiao and Weisberg 1997). The EUC core shoals, following the thermocline, from a maximum depth of about $150 \mathrm{~m}$ in the western Pacific to a minimum depth of approximately $50 \mathrm{~m}$ as it approaches the Galápagos Archipelago in the east (Johnson et al. 2001). The observed EUC has an estimated meridional extent of about 
(a)

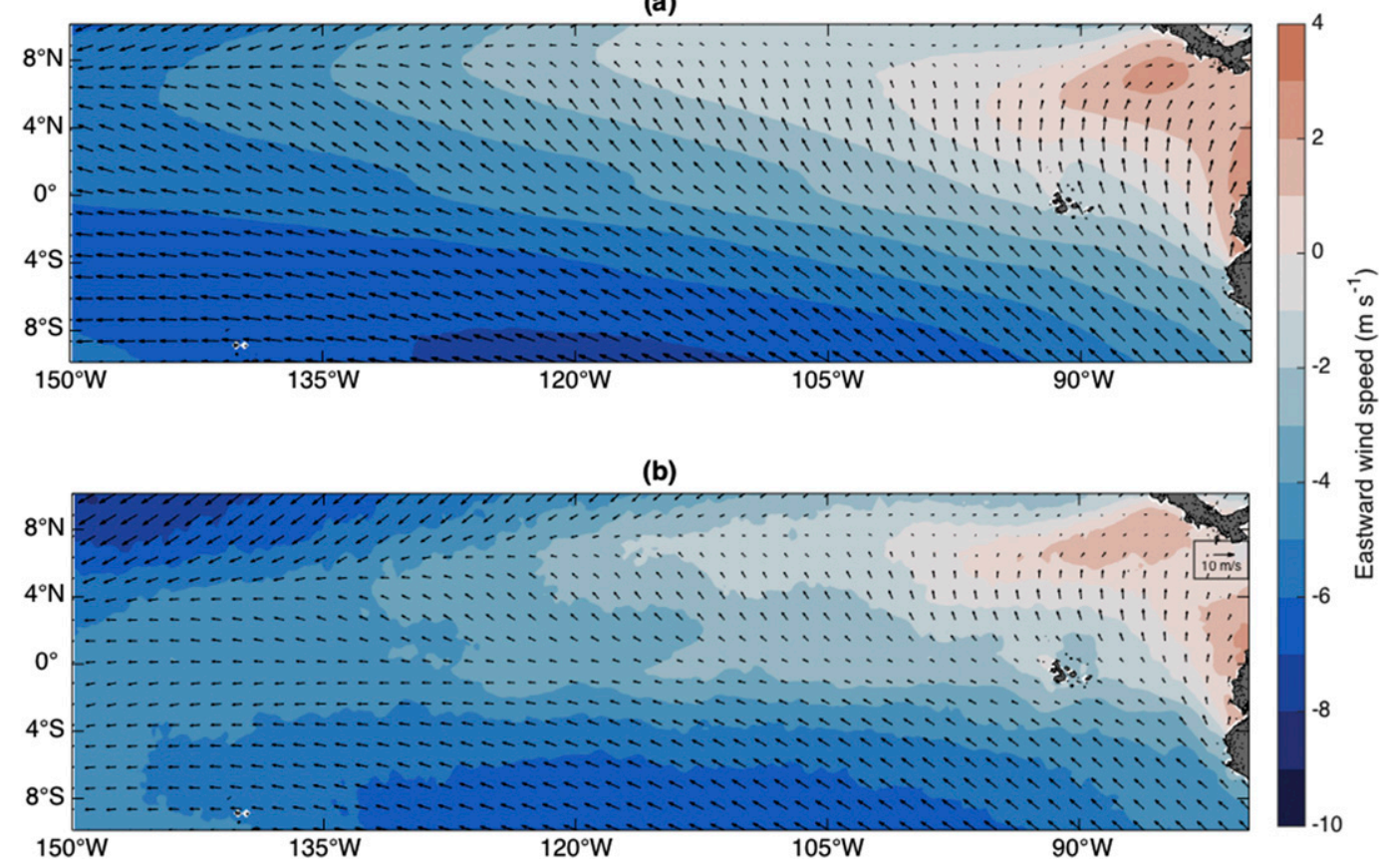

FIG. 2. Average 10-m winds in the equatorial Pacific during (a) all months from November 2008 to November 2018 and (b) April-May 2016 from the monthly $1 / 4^{\circ} \times 1 / 4^{\circ}$ CMEMS global wind product (Bentamy and Fillon 2012) provided by the E.U. Copernicus Marine Service. Colors show eastward wind speed, and vectors show total wind with a reference vector in (b).

$2^{\circ}$ of latitude, is centered about $0.5^{\circ}$ south of the equator due to upwind flow at the depth of the EUC associated with a meridional cell generated by average southerly winds (Mitchell and Wallace 1992), and has a vertical extent of $200 \mathrm{~m}$ (Qiao and Weisberg 1997; Johnson et al. 2002).

The strength of the EUC varies on a range of time scales. On seasonal scales, the EUC tends to be weaker from October through February and stronger from April to August near $95^{\circ} \mathrm{W}$ (Wyrtki and Meyers 1977; Johnson et al. 2002; Karnauskas et al. 2010). During El Niño years, trade winds decrease or reverse, thereby decreasing the zonal pressure gradient at the equator that drives the EUC. As a result, the EUC is significantly weakened (Johnson et al. 2002), except during the passage of Kelvin waves (Roundy and Kiladis 2006). Firing et al. (1983) show that this weakening can lead to a near reversal of the EUC, analogous to the atmospheric weakening of the Walker circulation associated with El Niño events (Bjerknes 1969; Lau and Yang 2015).

The EUC has been observed at the depth of the thermocline with a geostrophic broadening of the thermocline at the location of the EUC core (Wyrtki and Kilonsky 1984, their Fig. 2) due to relatively high zonal velocities (e.g., Wyrtki and Kilonsky 1984; Lukas 1986; Johnson et al. 2002). These studies also show a high salinity tongue extending into the EUC core from the south at the depth of the thermocline. This high salinity water originates in the subtropical South Pacific and is transported toward the equator by multiple pathways (e.g., Knauss 1966; Johnson and McPhaden 1999; Liu et al. 2014).

Few studies have attempted to characterize the path of the EUC around the Galápagos Archipelago, and related details of the eastern equatorial Pacific circulation remain unclear (Kessler 2006). Previous subsurface observations in the eastern equatorial Pacific consist mostly of relatively sparse shipboard ADCP data (e.g., Karnauskas et al. 2010) since the TAO array (Hayes et al. 1991) does not extend east of $95^{\circ} \mathrm{W}$. Lukas (1986) used hydrographic data to show that the high salinity tongue associated with the EUC remains intact east of the Galápagos Archipelago as far as $82^{\circ} \mathrm{W}$. Lukas (1986) also estimated geostrophic flow from dynamic topography, finding that the EUC splits around the Galápagos Archipelago with eastward flowing branches north and south of the islands. In a regional model, Karnauskas et al. (2007) showed that SST across the eastern equatorial Pacific is influenced by the presence of the Galápagos Archipelago, which impacts the EUC and characteristics of ENSO events (Karnauskas et al. 2008).

Here we use autonomous underwater glider observations from the Repeat Observations by Gliders in the 
(a)

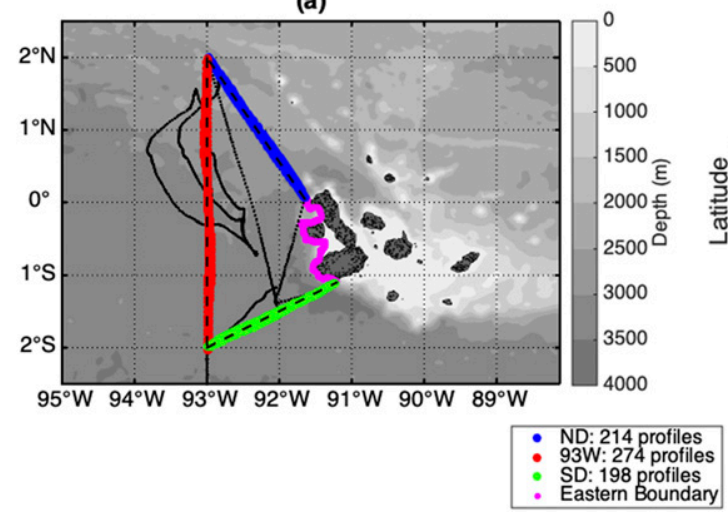

(b)

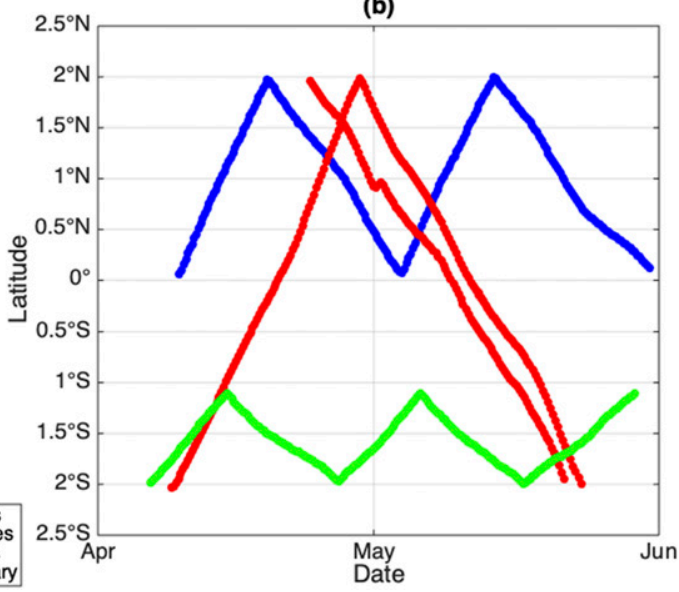

FIG. 3. (a) Trajectories of the four Spray glider missions west of the Galápagos Archipelago that are included in the analysis. Individual profiles within $30 \mathrm{~km}$ of ND (blue dot), 93W (red dot), and SD (green dot) used in the analysis are shown in color. Profiles not used in the analysis are shown by black dots. Dashed black lines indicate the three lines that the gliders occupied, defining the area of interest $A_{\mathrm{gl}}$. The magenta line connecting the eastern endpoints of ND and SD is the 300-m depth contour used to calculate $A_{\mathrm{gl}}$. The total number of profiles along each line is shown in the legend. (b) Sampling along ND (blue), 93W (red), and SD (blue) as a function of time and latitude.

Equatorial Region (ROGER) program to diagnose the flow of the EUC around the Galápagos Archipelago and to estimate areal-averaged upwelling between $93^{\circ} \mathrm{W}$ and the Galápagos Archipelago for a two-month period during which the region was well sampled. Section 2 describes the ROGER program and the glider observations used here. Section 3 presents average velocity fields (section 3a), describes the characteristics of horizontal volume transport associated with the EUC (section 3b) and provides an estimate of the time- and areal-averaged vertical velocity profile (section $3 \mathrm{c}$ ). Volume transport by salinity class is analyzed in section $3 \mathrm{~d}$ to determine the latitude along $93^{\circ} \mathrm{W}$ where a split of the EUC around the Galápagos Archipelago may occur. Section 4 examines implications of the results and comparisons to previous studies. Section 5 summarizes the results and addresses potential for future study.

\section{Observations and methods}

ROGER used a fleet of Spray gliders (Sherman et al. 2001; Rudnick et al. 2016) to observe the equatorial current system in the region west of the Galápagos Archipelago. From January 2013 through December 2016, a total of 19 glider missions surveyed along three lines bounding a region (hereafter referred to as $A_{\mathrm{gl}}$ ) to the west of the Galápagos Archipelago (Fig. 3a, dashed black lines). The fourth side of $A_{\mathrm{gl}}$ (Fig. 3a, magenta line) consists of Isla Isabela, the largest of the Galápagos Islands. The three glider survey lines were 1) the northern diagonal (hereafter referred to as ND), between the northwestern corner of Isla Isabela and $\left.2^{\circ} \mathrm{N}, 93^{\circ} \mathrm{W}, 2\right)$ $93^{\circ} \mathrm{W}$ from $2^{\circ} \mathrm{N}$ to $2^{\circ} \mathrm{S}$ (referred to as $93 \mathrm{~W}$ ), and 3 ) the southern diagonal (SD), between $2^{\circ} \mathrm{S}, 93^{\circ} \mathrm{W}$ and the southwestern corner of Isla Isabela. The sampling pattern was designed to capture the path of the EUC as it approaches the Galápagos Archipelago, guided by the modeling results of Karnauskas et al. (2010).

For closure of transport calculations, all three survey lines need to be occupied simultaneously and only fully occupied lines can be used to calculate transport for each transect. This limits our analyses to the period between 6 April 2016 and 31 May 2016 during which time four gliders surveyed the region (Fig. 3). Gliders were deployed from an oceanographic research vessel of the Ecuadorian Instituto Oceanográfico de la Armada near the south coast of Isla Isabela on 30 March 2016. Two missions followed SD toward $93^{\circ} \mathrm{W}$, subsequently occupying $93 \mathrm{~W}$. One mission each repeated transects along ND and SD. The four gliders were retrieved west of Isla Isabela on 20 July 2016. Three transects were completed along $93 \mathrm{~W}$, two of which were nearly coincident; ND and SD were occupied five and four times, respectively (Fig. 3b) between 6 April 2016 and 31 May 2016.

Each glider was equipped with a Sea-Bird SBE 41CP conductivity-temperature-depth sensor (CTD), a Seapoint chlorophyll fluorometer, and a 1-MHz Nortek AD2CP Doppler current profiler (Todd et al. 2017). All instruments sampled during the ascending portion of each glider dive from a maximum depth of $1000 \mathrm{~m}$ to the surface. CTD and fluorometer measurements were averaged to $10-\mathrm{m}$ vertical resolution after postprocessing 
(a)

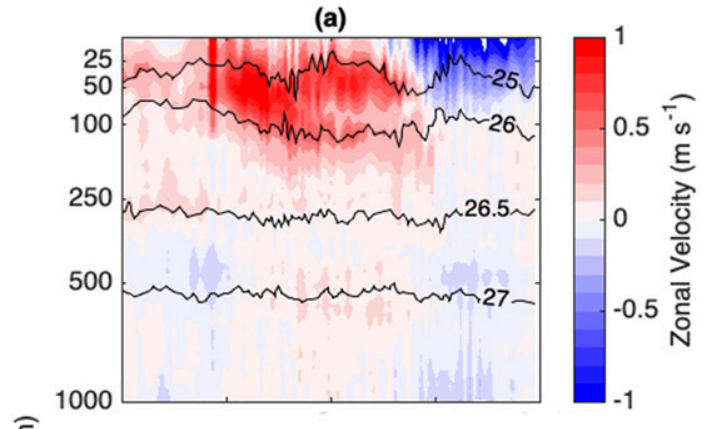

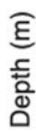

(c)

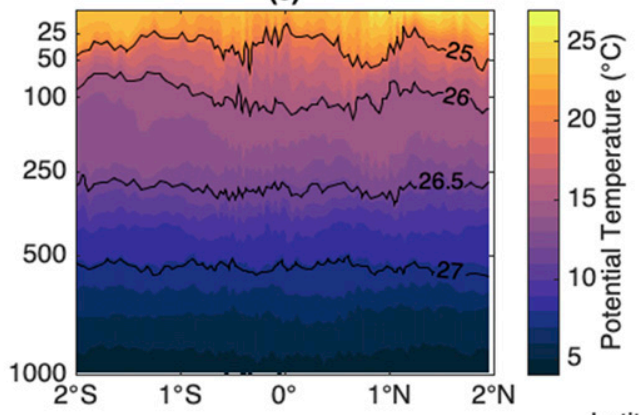

(b)

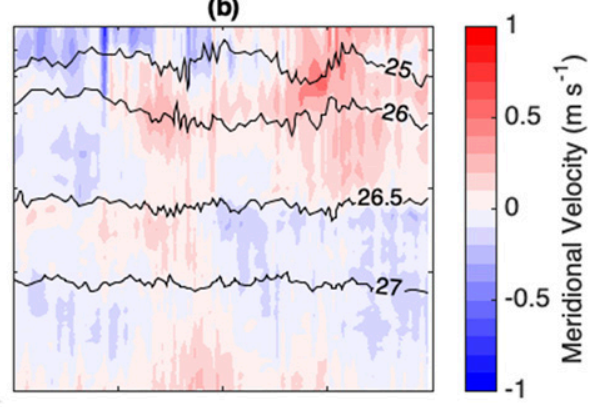

(d)

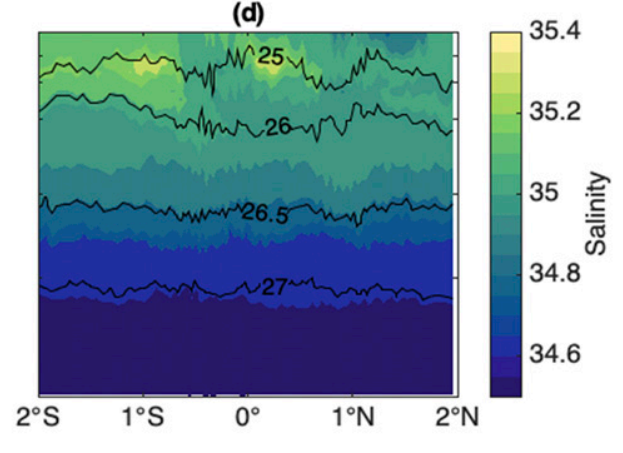

FIG. 4. Sections of (a) zonal velocity, (b) meridional velocity, (c) potential temperature, and (d) salinity in the upper $1000 \mathrm{~m}$ from one southbound transect along 93W from 29 Apr to 23 May 2016. Isopycnals $\left(\mathrm{kg} \mathrm{m}^{-3}\right)$ are shown in black. Note the depth axis is nonlinear to highlight variability in the upper $300 \mathrm{~m}$.

and quality control. Vertical profiles of absolute horizontal velocity at $10-\mathrm{m}$ resolution were estimated by combining absolute depth-average current estimates (Rudnick et al. 2018) with AD2CP-measured shear following Todd et al. (2017). An example transect (Fig. 4) resolves major features of the local equatorial current system, including a well-defined EUC core with maximum eastward velocity near $1 \mathrm{~m} \mathrm{~s}^{-1}$, a relatively strong westward surface flow north of the equator associated with the South Equatorial Current (SEC), and weaker meridional velocities.

Errors in temperature and salinity are small relative to the expected signal after quality control of individual measurements (Rudnick and Cole 2011). Obviously faulty observations due to instrument failure were flagged and excluded. The glider CTDs are highly accurate (Rudnick and Cole 2011), calibrated periodically at Sea-Bird, and checked prior to each mission using a transfer standard in the laboratory. Salinity and density observations are not available along ND during this time due to a CTD failure.

Accurate subsurface velocity estimates are critical to estimating horizontal volume transport. Estimated error associated with depth-average velocity measurements is $0.01-0.02 \mathrm{~m} \mathrm{~s}^{-1}$ (Rudnick et al. 2018), small compared with typical $O(1) \mathrm{m} \mathrm{s}^{-1}$ EUC velocities. Error in depthaverage velocity sets the absolute accuracy of velocity profiles (Todd et al. 2017). To estimate depth-dependent velocity errors, Todd et al. (2017) compared velocity profiles from two earlier ROGER glider missions that crossed paths three times while simultaneously occupying 93W. The root-mean-square (RMS) difference was between 0.07 and $0.09 \mathrm{~m} \mathrm{~s}^{-1}$ for those three crossings. RMS error of horizontal velocity for an individual profile reaches a minimum near the middle of the profile as a result of constraining velocity profiles to match measured depth-average velocity (Visbeck 2002) and increases with decreasing scatterers at depth. We assume that variance in the ocean should not increase with depth after a minimum value is reached. Following Todd et al. (2017), we compute profiles of velocity variance for 16 similarly equipped ROGER glider missions deployed along ND, 93W, and SD during April 2014-May 2016 (Fig. 5a). These profiles exhibit smaller increases in variance at depth than found in Todd et al. (2017) due to minor updates to quality control thresholds in postprocessing that admit a greater number of individual measurements of current velocity relative to the gliders. RMS errors in depth-dependent velocity for all ROGER missions that sampled to $1000 \mathrm{~m}$ are calculated as 
(a)

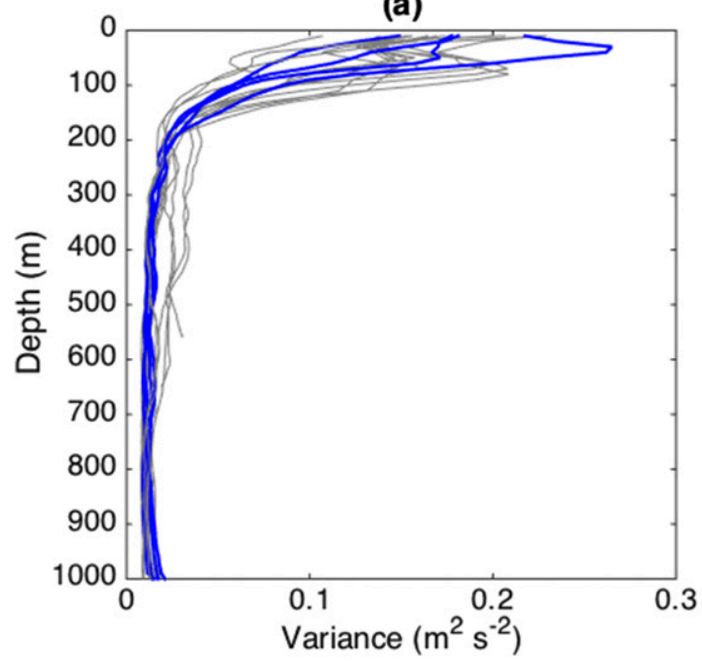

(b)

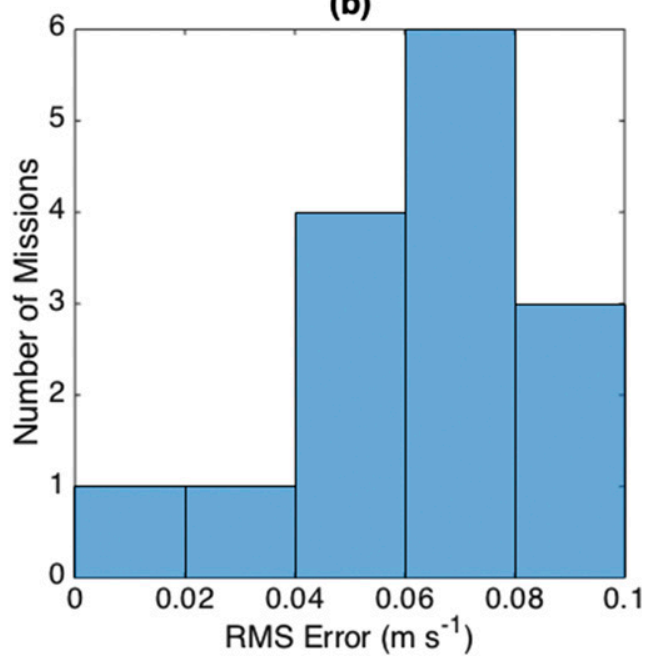

FIG. 5. (a) Profiles of velocity variance for each ROGER glider mission (gray) with the missions analyzed here highlighted in blue. (b) Histogram of RMS errors [Eq. (1)] for each of the 15 glider missions that sampled to $1000 \mathrm{~m}$.

$$
\sigma_{\mathrm{rms}}=\sqrt{\sigma_{1000 \mathrm{~m}}^{2}-\sigma_{z_{0}}^{2}}
$$

where $z_{0}$ is the depth of minimum variance for each mission (average $z_{0}=676 \mathrm{~m}$ ) and $\sigma^{2}$ is the variance over the length of the mission. RMS errors are typically $0.05-0.1 \mathrm{~m} \mathrm{~s}^{-1}$ (Fig. 5b). All further analyses include only observations obtained between 6 April 2016 and 31 May 2016.

\section{Results}

\section{a. Velocity observations along transects}

Average transects of flow across (normal to) and along 93W, SD, and ND during 6 April 2016-31 May 2016 are constructed by rotating velocities, gridding and smoothing individual transects, and finally averaging transects. Velocities below $300 \mathrm{~m}$ are small $\left(<0.1 \mathrm{~m} \mathrm{~s}^{-1}\right)$, consistent with Figs. $4 \mathrm{a}$ and $4 \mathrm{~b}$, and are not considered further. Velocities for each transect along the three lines are gridded onto a $15-\mathrm{km}$ horizontal grid using a Gaussian weighted average of the nearby data in order to smooth high-frequency variability. Following Rudnick et al. (2017), the Gaussian-weighting function $W(y)$ is

$$
W(y)=\exp \left[\frac{-(y-d)^{2}}{L^{2}}\right],
$$

where $d$ is the along-track position of a grid point, $L=15 \mathrm{~km}$ is the chosen scale of the Gaussian weight, and $y$ is along-track position of a measurement. The Gaussian scale is chosen based on the frequency at which there is a change in slope in the spectrum of normal velocity at 50-m depth, associated with high-frequency variability, consistent with the methods of Rudnick and Cole (2011) and Rudnick et al. (2017). The $L=15 \mathrm{~km}$ scale is equivalent to a period of approximately one day, filtering out tidal variations. The weighted average is

$$
u(d)=\sum_{i=1}^{m}\left[W\left(y_{i}\right) u\left(y_{i}\right)\right] / \sum_{i=1}^{m} W\left(y_{i}\right),
$$

where $u(d)$ represents gridded velocity (or other gridded field) and summation is over the $m$ observations within $80 \mathrm{~km}$ of the grid point, beyond which $W(y)<0.001$. Time average velocity $\bar{u}(d)$ is obtained by averaging the gridded velocity from Eq. (3) for all transects along each line. We assume that individual transects, lasting 10-20 days, are statistically independent and can be weighted equally, with the exception of those along $93 \mathrm{~W}$. Since two transects occur at nearly the same time along 93W (Fig. 3b), we average those two transects together before averaging the result with the remaining transect. Standard error estimates of the average sections of velocity are included in the appendix.

Average velocity normal to 93W during April-May 2016 (Fig. 6a) shows a clear EUC core with eastward flow peaking near $0.9 \mathrm{~m} \mathrm{~s}^{-1}$ at $50-\mathrm{m}$ depth and $0.7^{\circ} \mathrm{S}$. Measured near the end of the 2015/16 El Niño, this peak speed is higher than for the El Niño average calculated by Johnson et al. (2002), but lower than the La Niña average or the general long term average, possibly due to a combination of El Niño effects and the seasonal maximum in EUC velocity that occurs during AprilMay. During April-May 2016, the EUC core (normal velocity $>0.3 \mathrm{~m} \mathrm{~s}^{-1}$ ) extends roughly from the surface to 
(a)

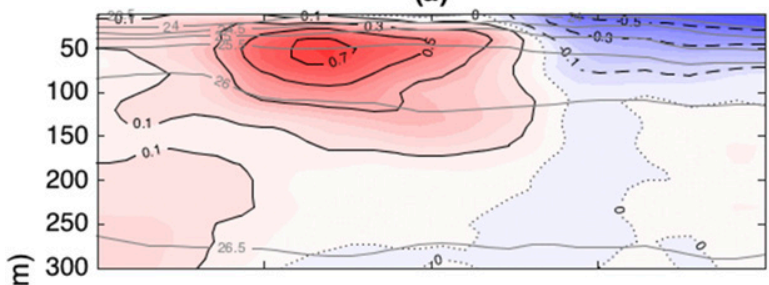

(b)
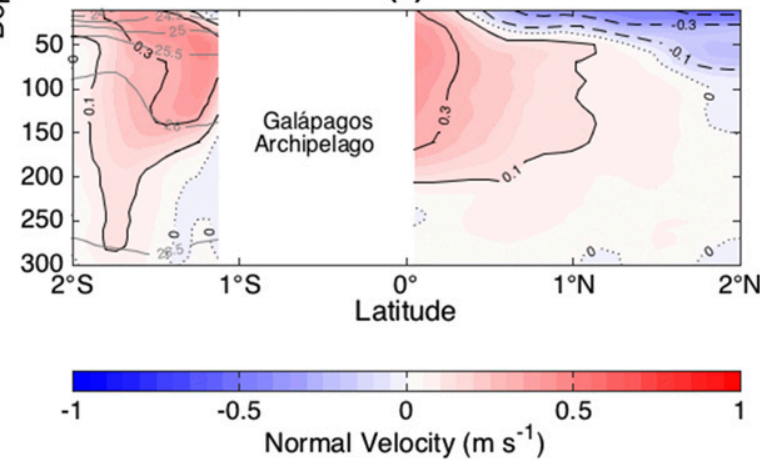

FIG. 6. Time average of velocity normal to (a) $93 \mathrm{~W}$ and (b) ND and SD above $300 \mathrm{~m}$. Positive (negative) velocities eastward (into $V_{\mathrm{gl}}$ ) along 93W. Positive velocities are out of $V_{\mathrm{gl}}$ along ND (northeastward) and SD (southeastward) for clarity in this figure only (elsewhere, all three survey lines use positive normal velocity into $\left.V_{\mathrm{gl}}\right)$. Isopycnals $\left(\mathrm{kg} \mathrm{m}^{-3}\right)$ are drawn gray and are not available for ND. The gap in (b) corresponds to the meridional extent of the Galápagos Archipelago.

$120-\mathrm{m}$ depth and from $1.25^{\circ} \mathrm{S}$ to $0.5^{\circ} \mathrm{N}$. North of the EUC, the westward SEC has a maximum velocity of $0.7 \mathrm{~m} \mathrm{~s}^{-1}$ and extends vertically from the surface to a depth of $75 \mathrm{~m}$ and meridionally from $0.5^{\circ} \mathrm{N}$ through the end of the line at $2^{\circ} \mathrm{N}$ based on westward velocities greater than $0.1 \mathrm{~m} \mathrm{~s}^{-1}$. These observations are consistent with previous studies of the equatorial current system along $95^{\circ} \mathrm{W}$ (Johnson et al. 2001, 2002).

Normal velocities along the two diagonals during April-May 2016 show the bifurcation of the EUC around the Galápagos Archipelago. Regions of high velocity out of the control volume $\left(V_{\mathrm{gl}}\right.$, defined by $A_{\mathrm{gl}}$, the 0 and $300-\mathrm{m}$ depth surfaces) are found across ND and SD (Fig. 6b) on both sides of the Galápagos Archipelago. The magnitude of maximum velocity out of the volume is $0.5 \mathrm{~m} \mathrm{~s}^{-1}$ along both ND and SD at depths of 60 and $70 \mathrm{~m}$, respectively, indicating that the speed of the EUC core decreases as the EUC branches around the Galápagos Archipelago, consistent with the results of Karnauskas et al. (2010).

The southern branch of the EUC extends from the surface to about $150-\mathrm{m}$ depth, with some weaker flow $\left(<0.2 \mathrm{~m} \mathrm{~s}^{-1}\right)$ reaching $300 \mathrm{~m}$. The northern branch extends from the surface to $200 \mathrm{~m}$, with very little flow at (a)

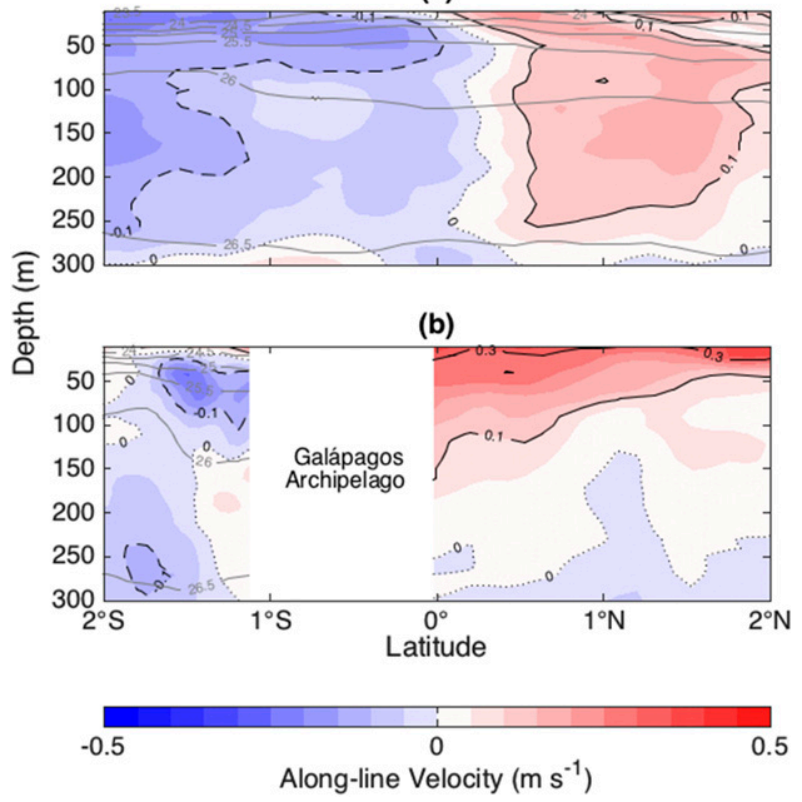

FIG. 7. As in Fig. 6, but for velocities tangent to (along) the survey lines. Positive (negative) velocities are northward (southward). Note that the velocity scale differs from that of Fig. 6.

greater depths. Thus, the decrease in maximum velocity along the two diagonals is also associated with increased vertical extent of the EUC as it flows around the Galápagos Archipelago. Flow between the archipelago and $93^{\circ} \mathrm{W}$ across SD is dominated by the EUC branching around the south side of the archipelago with negligible flow into $V_{\mathrm{g} \text { l }}$. Across ND, the north branch of the EUC is at a maximum close to the archipelago while flow reverses across ND north of $0.75^{\circ} \mathrm{N}$ where the SEC dominates.

Although our focus is velocity normal to each transect for the purpose of estimating volume transport, we note that along-track (meridional) velocity along $93 \mathrm{~W}$ is poleward from the surface to 280 -m depth (Fig. 7); this feature persists in a 3-yr average using observations from the full ROGER observing period (not shown). Near the surface, poleward velocities are likely a result of Ekman divergence (e.g., Wyrtki and Kilonsky 1984; Johnson et al. 2001; Perez and Kessler 2009). However, poleward velocities extend below the thermocline, deeper than a typical equatorial Ekman layer thickness of $100 \mathrm{~m}$ or less (e.g., Johnson et al. 2001; Perez and Kessler 2009) and deeper than expected for tropical cells (McCreary and Lu 1994). The ND section (Fig. 7b) is dominated by northwestward flow with maximum velocities at the surface due to a combination of SEC and Ekman transport. SD (Fig. 7b) has mostly southwestward along-track flow. The strongest flows along SD 
are normal to the line resulting in small along-track velocities.

\section{b. Net horizontal transport}

We now consider the net volume transport into $V_{\mathrm{gl}}$. For each transect, we define the "transport profile" $T_{n}(z)$ as the horizontal volume transport per unit depth $\left(\mathrm{m}^{2} \mathrm{~s}^{-1}\right.$ or $\left.\mathrm{Svm} \mathrm{m}^{-1} ; 1 \mathrm{~Sv} \equiv 10^{6} \mathrm{~m}^{3} \mathrm{~s}^{-1}\right)$. The transport profile $T_{n}(z)$ is calculated for individual transects by integrating normal velocity (without smoothing) over the length of the transect:

$$
T_{n}(z)=\int_{0}^{L} u(y, z) d y
$$

where $z$ is depth, $n$ is an index corresponding to transect number, $v$ is velocity normal to the section, $y$ is the along-track distance of each dive, and $L$ is total line length. The integral in Eq. (4) is evaluated discretely using a trapezoid rule.

The resulting transport profiles (Fig. 8) have maximum magnitudes above $300 \mathrm{~m}$. The magnitude of the transport through $93 \mathrm{~W}$ at the depth of the EUC core varies by nearly a factor of 3 between transects. Similar variations occur along the two diagonals, indicating that variability of the EUC and related transport occurs on time scales $O(20)$ days, which is the time between consecutive transects, and implying that most transects can be considered independent. RMS errors in absolute velocity profiles contribute small errors to our estimates of $T_{n}(z)$. For instance, for a $400-\mathrm{km}$ long transect along $93 \mathrm{~W}$ with 80 profiles uniformly spaced every $5 \mathrm{~km}$ and RMS velocity error of $0.1 \mathrm{~m} \mathrm{~s}^{-1}$ (section 2), standard error propagation yields an error in the transport profile of about $4 \times 10^{-3} \mathrm{~Sv} \mathrm{~m}^{-1}$, nearly two orders of magnitude smaller than the signals of interest (Fig. 8). As the transport errors due to errors in velocity estimates are dwarfed by transectto-transect variability, they are henceforth neglected in our calculations.

We calculate the average transport profile $\overline{T_{l}}(z)$ for each survey line $l(93 \mathrm{~W}, \mathrm{SD}$, and ND) by averaging $T_{n}(z)$ from individual transects, as in section $3 \mathrm{a}$. The standard error of the mean $\sigma_{\bar{T}}(z)$ is calculated at each depth level as

$$
\sigma_{\bar{T}}(z)=\frac{\sqrt{\sum_{n=1}^{N}\left[T_{n}(z)-\bar{T}_{l}(z)\right]^{2}}}{N} .
$$

Variability during the finite time (10-25 days) required for gliders to occupy individual transects is not accounted for in estimation of $\sigma_{\bar{T}}(z)$.

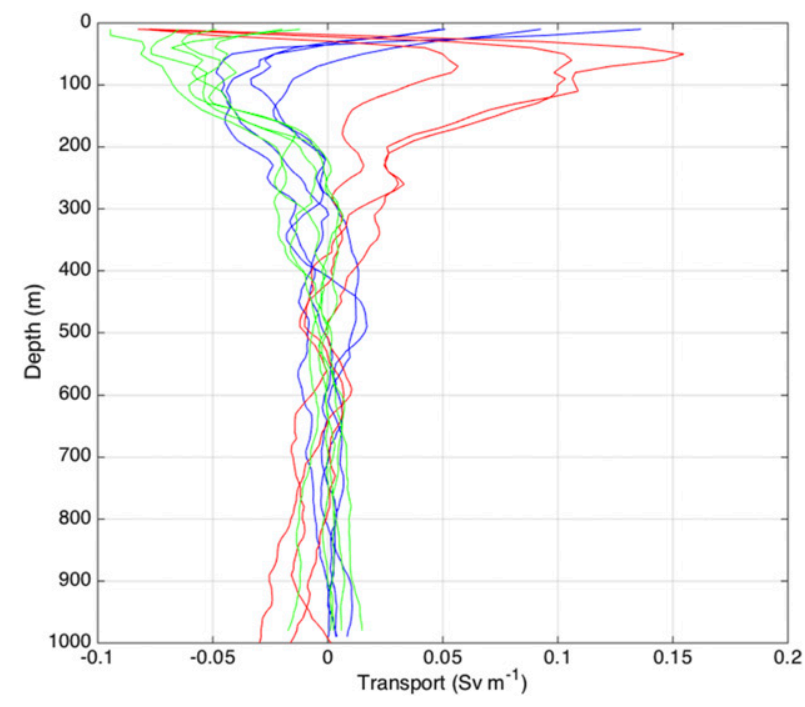

FIG. 8. Horizontal transport profiles $T_{n}(z)$ for all complete transects from 6 Apr 2016 through 31 May 2016 along ND (blue), 93W (red), and SD (green).

Consistent with average normal velocity (Fig. 6), average horizontal transport across 93W (Fig. 9a) tends to be positive (into $V_{\mathrm{gl}}$ ) below $20 \mathrm{~m}$ while average horizontal transports across SD and ND are generally negative (out of $V_{\mathrm{gl}}$ ). Positive transport across $93 \mathrm{~W}$ is primarily due to the EUC with its core centered near 50-m depth (Fig. 6a). Strong negative transport is confined to the surface, corresponding to the westward SEC. Negative horizontal transports across SD and ND peak around 50- and 100-m depth, respectively (Fig. 9a), reflecting splitting of the EUC core around the Galápagos Archipelago as it continues eastward. The sign of horizontal transport for ND changes from positive (0-40-m depth) to negative $(40-300 \mathrm{~m})$ due to the presence of the westward flowing SEC (positive horizontal transport) on the north side of the archipelago that extends from the surface to about $75-\mathrm{m}$ depth north of $0.5^{\circ} \mathrm{N}$ (Fig. 6b).

To differentiate between the generally eastward transport of the EUC and the generally westward transport of the SEC around the islands, we separately compute total, negative (out of $V_{\mathrm{gl}}$ ) and positive (into $V_{\mathrm{gl}}$ ) horizontal transport from the surface to $300-\mathrm{m}$ depth (Table 1) for each side of $V_{\mathrm{gl}}$. Nearly all of the volume transport of the EUC $(16.4 \pm 0.6 \mathrm{~Sv})$ bifurcates into two branches north and south of the Galápagos Archipelago, with higher transport to the south (10.9 \pm $0.1 \mathrm{~Sv}$ across SD versus $7.6 \pm 0.1 \mathrm{~Sv}$ across ND, Table 1 ). Subtracting the negative components of horizontal transport along ND and SD from the positive component along $93 \mathrm{~W}$ provides an estimate for the change in the EUC transport ( $\triangle$ EUC) between $93 \mathrm{~W}$ and the diagonals; $\Delta \mathrm{EUC}=-2.1 \pm 0.6 \mathrm{~Sv}$, so more flow exits 
(a)

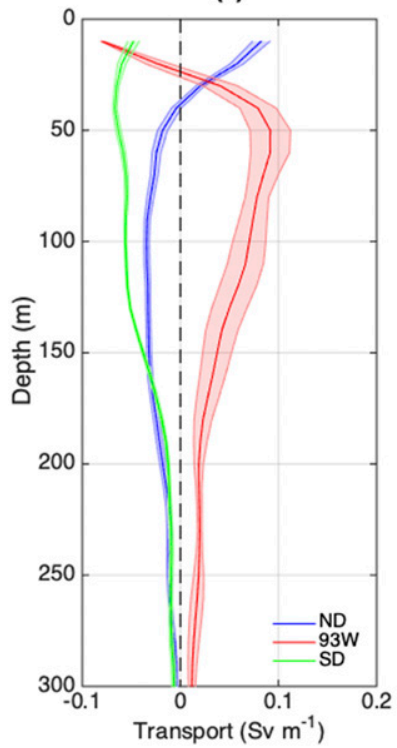

(b)

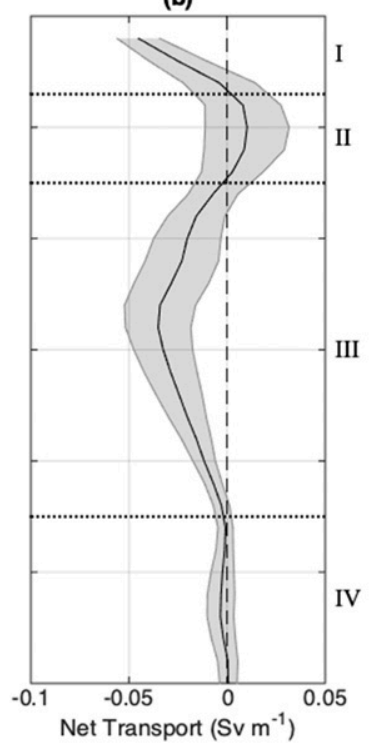

(c)

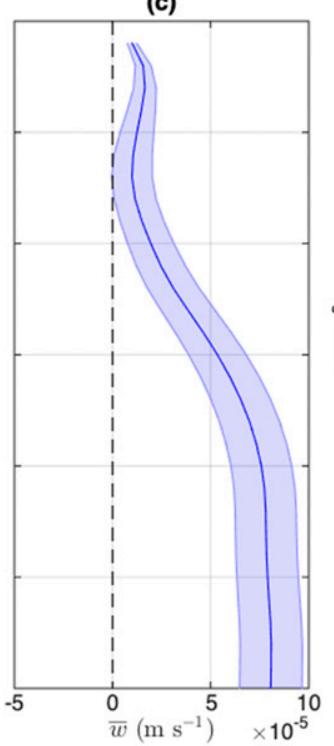

(d)

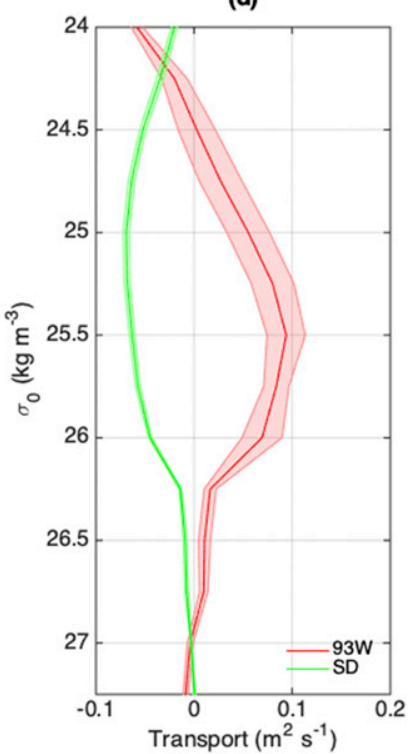

FIG. 9. Profiles of (a) average horizontal transport $\bar{T}_{l}(z)$, (b) net horizontal transport into the control volume, (c) vertical velocity, as a function of depth, and (d) horizontal transport as a function of potential density in the upper $300 \mathrm{~m}$. Shaded color error bars show standard errors. Dotted lines in (b) delineate depth layers I-IV.

$V_{\mathrm{gl}}$ along the diagonals than enters through $93 \mathrm{~W}$. Similarly, $\Delta \mathrm{SEC}=-2.3 \pm 0.2 \mathrm{~Sv}$ is defined as flow into the volume along ND minus flow out along $93 \mathrm{~W}$. Over the upper $300 \mathrm{~m}, \triangle \mathrm{EUC}$ and $\triangle \mathrm{SEC}$ are negative. The small positive transport along SD $(0.7 \pm 0.1 \mathrm{~Sv})$ leads to a net divergence in the upper $300 \mathrm{~m}$ of -3.6 $\pm 0.7 \mathrm{~Sv}$.

The three average transport profiles (Fig. 9a) are summed to give the average net transport profile $\bar{T}_{\text {net }}(z)$ into $V_{\mathrm{gl}}$ (Fig. 9b). For a given depth range, when the net transport profile is negative (positive), there is net horizontal divergence (convergence) averaged over the volume at that depth. The volume $V_{\mathrm{gl}}$ is divided by depth into four layers using the transport profile of Fig. $9 \mathrm{~b}$. These four layers are layer I, 5-35 m; layer II, 35-75 m; layer III, 75-225 m; and layer IV, 225-305 m (Fig. 10).

In layer I, EUC related flow is divergent (greater flow out along the diagonals than in across $93 \mathrm{~W}$ ). Net divergence in layer $I$ is dominated by strengthening of the SEC between its entry into $V_{\mathrm{gl}}$ across ND and its exit across $93 \mathrm{~W}$, primarily due to the entrainment of upwelled waters and the northern branch of the split EUC as it is deflected northward by the archipelago (Fig. 10a). However, since both $\triangle E U C$ and $\triangle$ SEC are negative, there must be an additional source of volume transport into layer I. Ekman divergence likely contributes to net divergence via poleward flow on both sides of the equator, as indicated by tangential (alongtrack) velocities along ND and near $0.5^{\circ} \mathrm{N}$ along $93 \mathrm{~W}$ (Figs. 7 and 10a).
Net convergence in layer II (Fig. 9b) results from greater transport into $V_{\mathrm{gl}}$ by the EUC core across $93 \mathrm{~W}$ compared with the combined transport out of $V_{\mathrm{gl}}$ along the diagonals (Fig. 10b). While there is net convergence in this layer, SEC divergence is stronger than in layer I, which implies there must be additional mechanisms resulting in a net convergence. Layer II convergence may be driven by vertical spreading of the split EUC, resulting in decreased transport out of $V_{\mathrm{gl}}$ along the diagonals within layer II, and topographic upwelling of the EUC as it reaches the Galápagos Archipelago. Below layer II, vertical spreading of the split EUC results in increased transport out of $V_{\mathrm{gl}}$ along the diagonals.

Net divergence in layer III over $A_{\mathrm{gl}}$, below the EUC core, is partially a result of greater EUC related flow out of $V_{\mathrm{gl}}$ across the diagonals than in across 93W (Figs. 6 and 10c). However, the transport out of $V_{\mathrm{gl}}$ in layer III has a greater magnitude than transport into $V_{\mathrm{gl}}$ in layer II, which indicates that the net divergence cannot be

TABLE 1. Average transport (Sv) and standard error normal to each line above $300 \mathrm{~m}$. Negative (positive) transport is calculated by summing over only negative (positive) velocities. Positive indicates into the control volume.

\begin{tabular}{crrr}
\hline \hline Transport component & \multicolumn{1}{c}{ ND } & \multicolumn{1}{c}{$93 \mathrm{~W}$} & \multicolumn{1}{c}{ SD } \\
\hline Negative & $-7.6 \pm 0.1$ & $-6.0 \pm 0.2$ & $-10.9 \pm 0.1$ \\
Positive & $3.7 \pm 0.1$ & $16.4 \pm 0.6$ & $0.7 \pm 0.1$ \\
Total & $-3.9 \pm 0.2$ & $10.5 \pm 0.7$ & $-10.1 \pm 0.1$
\end{tabular}


(a) Layer I: 5 - $35 \mathrm{~m}$

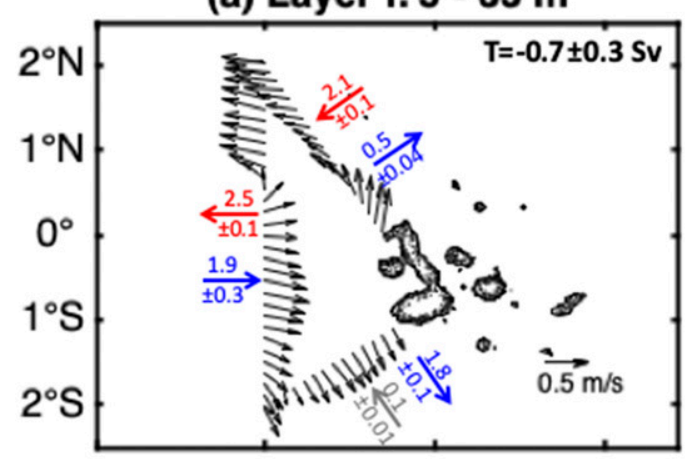

(c) Layer III: 75 - $225 \mathrm{~m}$

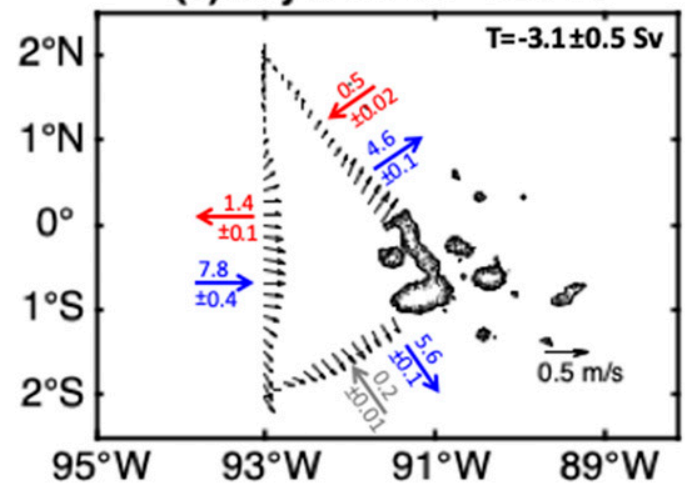

(b) Layer II: 35 - 75 m

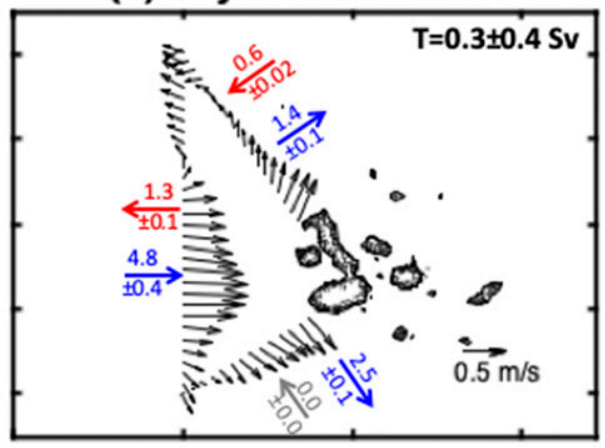

(d) Layer IV: 225 - $305 \mathrm{~m}$

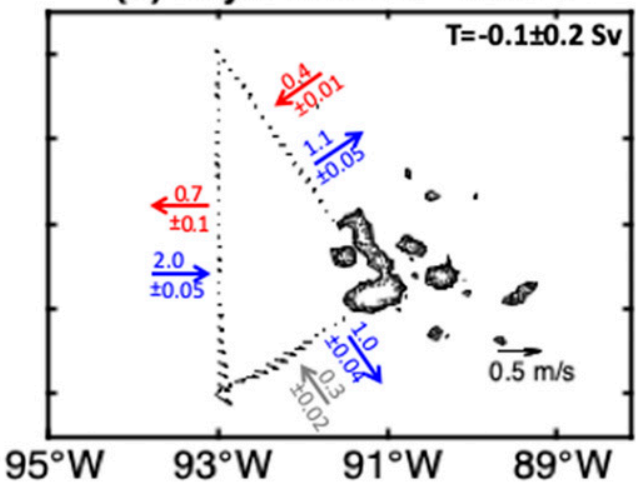

FIG. 10. Time- and depth-average velocity (black vectors) for (a) layer I, 5-35 m, (b) layer II, 35-75 m, (c) layer III, 75-225 m, and (d) layer IV, 225-305 m. Numerical values and associated colored arrows represent horizontal transport (Sv) in each layer. Red indicates flow associated with the SEC (in across ND, out across 93W), blue is flow associated with the EUC (in across 93W, out across ND and SD), and gray arrows indicate flow not directly associated with the EUC or SEC. Shown at the upper right, $T$ is the net horizontal transport into the control volume in each layer.

accounted for solely by downwelling of EUC waters as the EUC splits into two branches. Below the EUC, SEC, and Ekman transport, layer IV is nearly nondivergent (Fig. 10d). Net divergence over the upper $300 \mathrm{~m}$ is discussed further in section 4.

To provide insight into the mechanisms behind vertical spreading of the EUC branches compared to the incoming EUC across 93W, we calculate average horizontal volume transport profiles across $93 \mathrm{~W}$ and SD as functions of potential density by interpolating velocity estimates onto potential density surfaces prior to calculating volume transport (Fig. 9d; ND density is unavailable due to CTD failure). The horizontal transport maximum along $93 \mathrm{~W}$ and subsequent decrease toward zero below $\sigma_{0}=26.5 \mathrm{~kg} \mathrm{~m}^{-3}$ occur on the same potential density surfaces as along SD (Fig. 9d). Between 93W and SD, imbalances in horizontal transport along fixed depths below $75 \mathrm{~m}$ are in part due to isopycnal spreading and flow across ND. Above $\sigma_{0}=25 \mathrm{~kg} \mathrm{~m}^{-3}$, transport across $93 \mathrm{~W}$ and $\mathrm{SD}$ are negative, presumably due to flow into $V_{\mathrm{gl}}$ across ND. Despite the lack of ND potential density observations, the alignment of local maxima and minima below $\sigma_{0}=25.5 \mathrm{~kg} \mathrm{~m}^{-3}$ along 93W and SD suggests along-isopycnal flow at these depths.

\section{c. Vertical velocity}

Integrating the average net horizontal transport profile (Fig. 9b) from the surface to 300-m depth gives a net transport of $3.6 \pm 0.7 \mathrm{~Sv}$ out of the volume. The average vertical velocity required at $300 \mathrm{~m}$ to balance this horizontal divergence is $(8.0 \pm 1.6) \times 10^{-5} \mathrm{~m} \mathrm{~s}^{-1}$, indicating net upwelling during the observed time period. To estimate $\bar{w}(z)$, the time- and areal-averaged vertical velocity profile in the region $A_{\mathrm{gl}}$, we time average $(\langle\cdot\rangle)$ the incompressible continuity equation, solve for $\partial\langle w\rangle / \partial z$, average over $A_{\mathrm{gl}}$, and apply the divergence theorem to obtain

$$
-\frac{1}{A_{\mathrm{gl}}} \iint_{A_{\mathrm{gl}}} \frac{\partial\langle w\rangle}{\partial z} d A=\frac{1}{A_{\mathrm{gl}}} \int_{P}\langle u\rangle d y=\frac{1}{A_{\mathrm{gl}}} \bar{T}_{\mathrm{net}},
$$


where $\langle u(y, z)\rangle$ is time-average horizontal velocity normal to ND, $93 \mathrm{~W}$, and $\mathrm{SD}$, and $P$ is the perimeter of $A_{\mathrm{gl}}$. We then estimate $\bar{w}(z)$ by integrating the average horizontal volume transport profile $\bar{T}_{\operatorname{net}(z)}$ vertically as

$$
\bar{w}(z)=-\frac{1}{A_{\mathrm{gl}}} \int_{z}^{z_{0}} \bar{T}_{\mathrm{net}}(z) d z,
$$

where $z$ is positive upward and we assume that $w=0$ at $z_{0}=-10 \mathrm{~m}$, the shallowest depth at which velocity is estimated. The value of $A_{\mathrm{gl}}=4.51 \times 10^{4} \mathrm{~km}^{2}$ is the area of the region with maximum depth greater than $300 \mathrm{~m}$ within the polygon defined by the three glider survey lines and Isla Isabela (Fig. 3). The standard error of the average of vertical velocity $\sigma_{\bar{w}}(z)$ is

$$
\sigma_{\bar{w}}(z)=\int_{z}^{z_{0}} \sigma_{\bar{T}}(z) d z
$$

where $\sigma_{\bar{T}}(z)$ is defined in Eq. (5).

Above $50 \mathrm{~m}$ (Fig. 9c), significant upwelling is consistent with SST observations of Fig. 1 due to horizontal divergence (negative net transport) that exists above the EUC core (layer I, Fig. 10a). The local maximum vertical velocity is $(1.7 \pm 0.6) \times 10^{-5} \mathrm{~m} \mathrm{~s}^{-1}$ (or $1.5 \pm 0.5 \mathrm{~m} \mathrm{day}^{-1}$ ) at 25-m depth. Vertical motions are small compared to horizontal motions, so standard error associated with vertical velocity is high compared to the magnitude of $\bar{w}(z)$ and $\bar{w}(z)$ is not significantly different than zero from about 50 to $100 \mathrm{~m}$. Vertical velocity decreases below $30 \mathrm{~m}$ from the near surface peak until it reaches a minimum near $75 \mathrm{~m}$ (Fig. 9c), corresponding to the region where the EUC core is strongest and there is net convergence in layer II (Fig. 10b).

Below $75 \mathrm{~m}$, positive vertical velocity (Fig. 9c) is primarily attributed to increased vertical extent of the north and south branches of the EUC core in layer III compared to the EUC core along $93 \mathrm{~W}$ in layer II as it reaches the archipelago (Fig. 10c) and meridional divergence in the upper $300 \mathrm{~m}$ (Fig. 7), resulting in net divergence in layer III. Vertical velocity is nearly constant below $225 \mathrm{~m}$, consistent with near zero divergence in layer IV. The maximum vertical velocity of $(8.0 \pm 1.6) \times 10^{-5} \mathrm{~m} \mathrm{~s}^{-1}$ occurs at a depth of $300 \mathrm{~m}$.

\section{d. Volume transport by salinity class}

Using the methods of section $3 \mathrm{a}$, we calculate average salinity along 93W and SD (Fig. 11). A major feature of the average salinity section along $93^{\circ} \mathrm{W}$ (Fig. 11a) is the subsurface salinity maximum (salinity $>35.1$ ) from $0.5^{\circ} \mathrm{S}$ to $2^{\circ} \mathrm{S}$ at the depth of the EUC core $(50 \mathrm{~m})$. High salinity water originates in the subtropical South Pacific (Knauss 1966; Fiedler and Talley 2006) and is transported equatorward via multiple pathways (Johnson and McPhaden 1999).

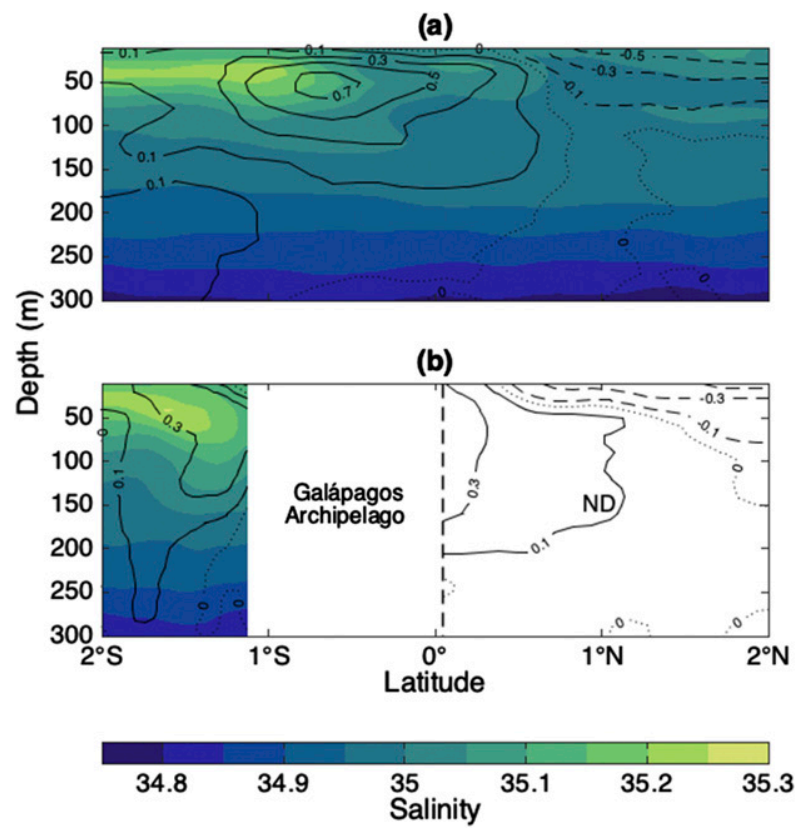

FIG. 11. As in Fig. 6, but for salinity. The dashed line in (b) delineates the Galápagos Archipelago from ND, where salinity observations were not available. Contours of normal velocity $\left(\mathrm{m} \mathrm{s}^{-1}\right)$ are shown in black; negative velocity contours are dashed.

The high salinity (35.2-35.25) tongue observed along $93 \mathrm{~W}$ is bounded by the 24.5 and $25.5 \mathrm{~kg} \mathrm{~m}^{-3}$ isopycnals, consistent with observations of Johnson and McPhaden (1999) along $125^{\circ} \mathrm{W}$. There is an additional local salinity maximum at a depth of $50 \mathrm{~m}$ between the equator and $0.5^{\circ} \mathrm{N}$, consistent with transient extensions north of the equator in the central Pacific on monthly time scales as described by Johnson et al. (2000).

A high salinity tongue similar in shape to that along 93W also exists along SD (Fig. 11b). The SD high salinity tongue slopes downward from $2^{\circ} \mathrm{S}$ to $1.1^{\circ} \mathrm{S}$ from a depth of 20 to $70 \mathrm{~m}$, following sloping isopycnals and consistent with deepening of the EUC as it branches around the Galápagos Archipelago. The salinity section along SD closely matches in magnitude and spatial pattern the section along $93 \mathrm{~W}$ between $2^{\circ} \mathrm{S}$ and about $0.4^{\circ} \mathrm{S}$, indicating that much of the water south of $0.4^{\circ} \mathrm{S}$ entering the volume across $93 \mathrm{~W}$ exits out the SD. High salinity water exiting along SD has similar temperature and salinity properties to the high salinity tongue along 93W (Fig. 12). However, SD includes water of higher salinity. This discrepancy could be due to slight differences in sampling coverage between the two lines (Fig. 3b) as the higher salinity water in the average section is the result of a single SD transect.

We now consider volume transport as a function of salinity class along 93W and SD, adapting our methodology 
(a)

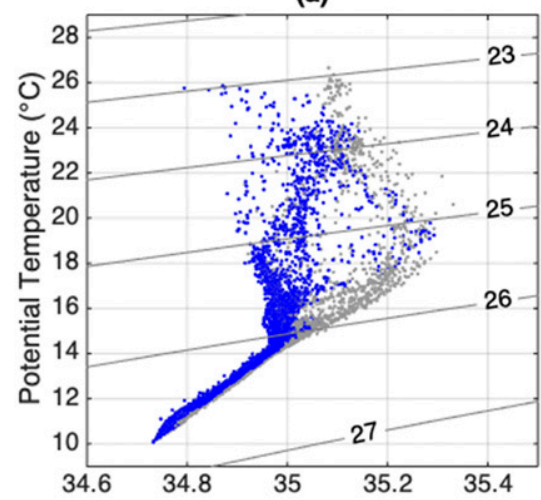

(b)

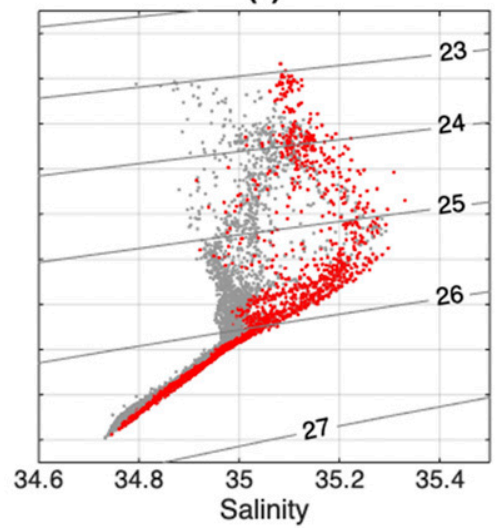

(c)

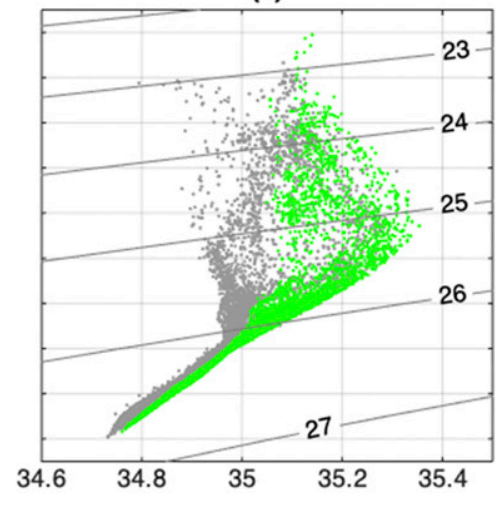

FIG. 12. Potential temperature-salinity diagram along (a) $93 \mathrm{~W}$ north of $0.4^{\circ} \mathrm{S}$ (blue), (b) along $93 \mathrm{~W}$ south of $0.4^{\circ} \mathrm{N}$ (red), and (c) along $\mathrm{SD}$ (green). In (a)-(c), all potential temperature-salinity pairs along $93 \mathrm{~W}$ between $2^{\circ} \mathrm{S}$ and $2^{\circ} \mathrm{N}$ are shown with gray dots. Isopycnals $\left(\mathrm{kg} \mathrm{m}^{-3}\right)$ are shown in gray contours.

from section $3 \mathrm{~b}$. We compute the cumulative volume transport of waters in the upper 300 with salinity less than salinity $S$ through $93 \mathrm{~W}$ and SD as

$$
T_{n}(S)=\int_{300 \mathrm{~m}}^{z=10 \mathrm{~m}} \int_{0}^{L} u(y, z) H[S-s(y, z)] d y d z,
$$

where $n$ is the index corresponding to a single transect, $H$ is the heaviside function, $S$ is the upper salinity bound, $s(y, z)$ is the observed salinity, and $L$ is the length of the line. The term $\bar{T}_{l}(S)$ is the time average of $T_{n}(S)$ for a given survey line, where subscript $l$ indicates $93 \mathrm{~W}$ or SD. Standard error for $\bar{T}_{l}(S)$ is

$$
\sigma_{l}(S)=\frac{\sqrt{\sum_{n=1}^{N}\left[T_{n}(S)-\overline{T(S)}\right]^{2}}}{N} .
$$

Volume transport is into the volume along $93 \mathrm{~W}$ for all salinity classes as indicated by the monotonically increasing cumulative transport (Fig. 13a, red); similarly, transport is out of the volume for all salinity classes along SD (Fig. 13a, green). Volume transport as a function of salinity along ND is estimated by assuming that net horizontal volume transport is zero for each $S$ so that $\bar{T}_{\mathrm{ND}}(S)=-\left[\bar{T}_{93 \mathrm{~W}}(S)+\bar{T}_{\mathrm{SD}}(S)\right]$. For salinities above 35 , transport into $V_{\mathrm{gl}}$ across $93 \mathrm{~W}$ is nearly equal to transport out across SD, as indicated by nearly constant cumulative transport of salinities above 35 along ND (Fig. 13a). The high salinity tongue transported into $V_{\mathrm{gl}}$ across $93 \mathrm{~W}$ leaves through SD. In the salinity range $34.9-35$, waters flowing in across $93 \mathrm{~W}$ are not accounted for by flow out across SD, implying transport of those waters out of $V_{\mathrm{gl}}$ across ND.

To examine the meridional dependence of these results, we recompute $T_{93 \mathrm{~W}}(S)$ using only observations between $2^{\circ} \mathrm{S}$ and $0.4^{\circ} \mathrm{S}$ along the $93 \mathrm{~W}$ line (Fig. 13b). The cutoff latitude of $0.4^{\circ} \mathrm{S}$ was obtained by minimizing the average squared difference between $T_{93 \mathrm{~W}}(S)$ and $T_{\mathrm{SD}}(S)$, such that residual transport through ND was as small as possible for all $S$ (Fig. 13b). This latitude can be interpreted as the boundary where the EUC splits into north and south branches around the Galápagos Archipelago. Deviation from zero transport through ND (positive or negative slopes) is indicative of variation of the bifurcation latitude with depth.

Upon reaching the Galápagos Archipelago, the EUC splits into a north and south branch. Water south of $0.4^{\circ} \mathrm{S}$ flows south around the archipelago, while water north of the cutoff latitude flows north around the islands. The cutoff latitude south of which nearly all water that enters $V_{\mathrm{gl}}$ across $93 \mathrm{~W}$ exits along SD is close to the latitude of the center of the Galápagos Archipelago and the approximate average latitude of the EUC core during this time period (Fig. 6). Water mass properties in the south branch of the EUC match those of waters in the southern half of the EUC along 93W (Fig. 12). Since the north branch of the EUC exits $V_{\mathrm{gl}}$ along ND, it is likely that a similar scenario occurs north of $0.4^{\circ} \mathrm{S}$.

\section{Discussion}

\section{a. EUC transport and bifurcation}

Total volume transport of the EUC across $93 \mathrm{~W}$ $(16.4 \pm 0.6 \mathrm{~Sv})$ in this study is less than previous estimates of 20-30 Sv in the central Pacific (Lukas and Firing 1984; Wyrtki and Kilonsky 1984), due to the well-known weakening of the EUC as it moves eastward (Johnson et al. 2002), possible effects of the 2015/16 El Niño, and/or the annual cycle of wind stress in the equatorial Pacific (Kessler et al. 1998). These discrepancies 
(a)

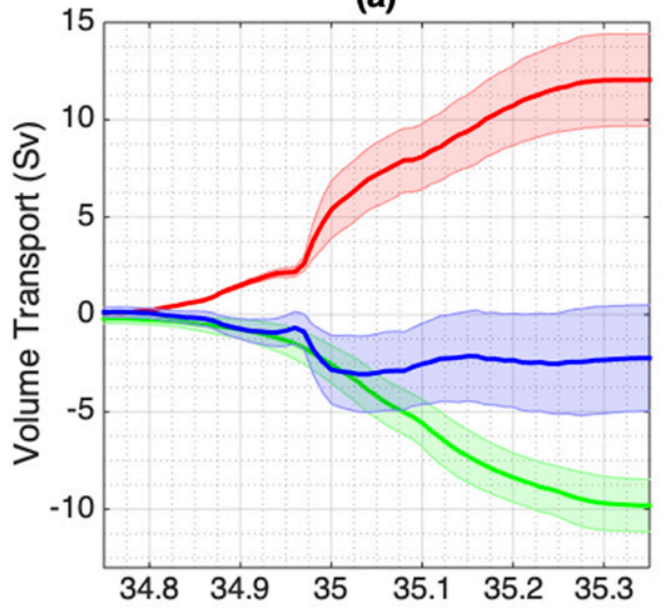

(b)

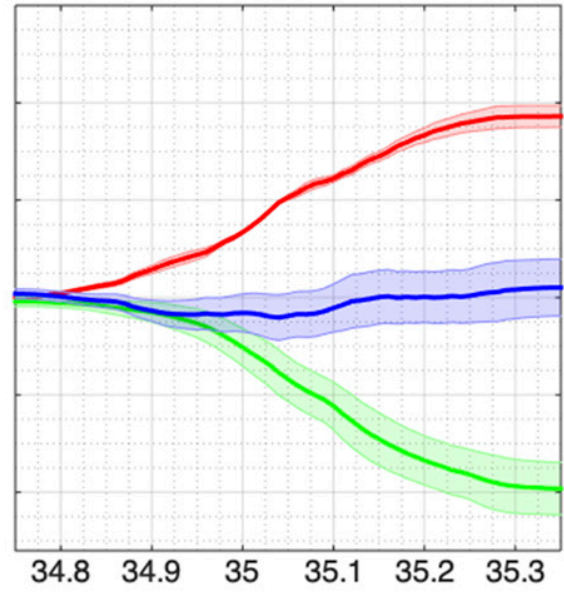

Salinity

FIG. 13. (a) Cumulative volume transport as a function of salinity for $93 \mathrm{~W}$ (red) and SD (green). Cumulative transport through ND is calculated as a residual due to the lack of CTD data. Shading shows standard errors. Positive transport is into the control volume. (b) As in (a), but for transport through $93 \mathrm{~W}$ only south of $0.4^{\circ} \mathrm{S}$.

in EUC transport between studies are due to temporal and spatial differences.

The bifurcation of the EUC along $92^{\circ} \mathrm{W}$ was previously estimated by Lukas (1986) using a climatological average of historical observations between $100^{\circ}$ and $80^{\circ} \mathrm{W}$. Because these sections were taken on either side of the Galápagos Archipelago, the splitting of the two branches was not directly observed. However, the beginnings of the split into a north and south branch were evident along $92^{\circ} \mathrm{W}$ with a north branch extending down to $400 \mathrm{~m}$, much deeper than the weaker south branch. Along $88^{\circ} \mathrm{W}$, two eastward branches existed on either side of the equator, with the stronger branch to the north. During April-May 2016, our analysis shows two nearly equal branches with similar vertical extent to $200 \mathrm{~m}$. Volume transport as a function of salinity shows that the meridional boundary where the split between the branches occurs is at $0.4^{\circ} \mathrm{S}$, just north of the meridional center of the Galápagos Archipelago and the EUC core. Figure $13 \mathrm{~b}$ indicates that the high salinity tongue, extending equatorward from the Southern Hemisphere, is advected south of the Galápagos Archipelago as the EUC splits into north and south branches. Differences between our results and those of Lukas (1986) may be due to temporal differences between the two studies relative to annual and ENSO cycles.

Model analyses have suggested that the path of the EUC around the Galápagos Archipelago may have impacts on the local ecosystem (Karnauskas et al. 2015), the equatorial Pacific cold tongue (Karnauskas et al. 2007), and the basic state of the tropical Pacific (Karnauskas et al. 2014). These results are also sensitive to model resolution of the EUC (Karnauskas et al. 2008). Validation of model results requires observations of the path of the EUC just west of the Galápagos Archipelago, such as those presented here. Additionally, it is unknown to what degree and by what pathway the EUC contributes to the eastern equatorial Pacific cold tongue that extends westward from the coast of South America (Wyrtki 1966; Philander 1973; Kessler 2006; Karnauskas et al. 2007). This study does not directly address the latter question, but the observed bifurcation of the EUC (Fig. 6) indicates that the two branches may reach the eastern Pacific cold tongue east of the Galápagos Archipelago at $90^{\circ} \mathrm{W}$ (Fig. 1) while maintaining most of the zonal transport of the EUC prior to its encounter with the Galápagos Archipelago.

\section{b. Upwelling and the GCP}

The average vertical velocity profile indicates upwelling throughout the upper $300 \mathrm{~m}$, with maximum value of $8.0 \pm 1.6 \times 10^{-5} \mathrm{~m} \mathrm{~s}^{-1}$ or $6.9 \pm 1.4 \mathrm{~m} \mathrm{day}^{-1}$ at $300 \mathrm{~m}$ (Fig. 9c). While this upwelling rate is large by open-ocean standards, we expect vertical velocity in the region of $A_{\mathrm{gl}}$ to differ from the general equatorial upwelling reported by previous studies (e.g., Weisberg and Qiao 2000; Johnson et al. 2001; Wyrtki 1981) due to the presence of the Galápagos Archipelago, which adds the possibility of topographic upwelling that is not a factor in the central Pacific. The existence of the local minimum in SST within the GCP (Fig. 1) suggests that the region between $93^{\circ}$ and $91.5^{\circ} \mathrm{W}$ is characterized by enhanced upwelling compared to the central equatorial Pacific. A major difference between our estimated upwelling 
and estimates in previous studies is that the average vertical velocity profile estimated here has high values below the EUC core.

\section{1) COMPARISON TO OTHER ESTIMATES}

Our estimate of upwelling above $50 \mathrm{~m}$, with maximum value of $(1.7 \pm 0.6) \times 10^{-5} \mathrm{~m} \mathrm{~s}^{-1}$ at $25 \mathrm{~m}$, is slightly less than the maximum of $1.9-2.0 \times 10^{-5} \mathrm{~m} \mathrm{~s}^{-1}$ reported by Weisberg and Qiao (2000) at $140^{\circ} \mathrm{W}$ and by Johnson et al. (2001) at $170^{\circ}-95^{\circ} \mathrm{W}$, but agrees within the standard error. Wyrtki (1981) estimated upwelling across the 50-m depth surface in the central Pacific to be $1.1 \times$ $10^{-5} \mathrm{~m} \mathrm{~s}^{-1}$, while Meinen et al. (2001) estimated it to be $0.3 \times 10^{-5} \mathrm{~m} \mathrm{~s}^{-1}$ at $50-\mathrm{m}$ depth and $95^{\circ} \mathrm{W}$, both less than our estimate. These differences may be attributed to a combination of the following:

(i) Discrepancies in upwelling between studies are impacted by the relatively broad meridional extent of $A_{\mathrm{gl}}$, as Johnson et al. (2001) showed that the maximum in equatorial upwelling occurs along the equator and decreases with increasing latitude. The western (93W) and eastern (Galápagos Archipelago) boundaries of $A_{\mathrm{gl}}$ span $4^{\circ}$ and $1.1^{\circ}$ latitude about the equator, respectively, with the centroid of $A_{\mathrm{gl}}$ located slightly south of the equator at $0.3^{\circ} \mathrm{S}$. Weisberg and Qiao (2000) and Johnson et al. (2001) obtained higher vertical velocity estimates from observations that spanned $2^{\circ}$ across the equator. Wyrtki (1981) and Meinen et al. (2001) used data from meridional ranges of $4^{\circ}$ and $10^{\circ}$ latitude centered around the equator, respectively, and arrive at estimates less than the one in this study. Our estimated $\bar{w}(z)$ is an average over $A_{\mathrm{gl}}$, yet the SST minimum associated with the GCP (Fig. 1) is confined to a fraction of $A_{\mathrm{gl}}$. If upwelling associated with the GCP occurs over an area smaller than $A_{\mathrm{gl}}$, then vertical velocity over the smaller area is proportionally stronger than that in Fig. 9c.

(ii) The spatial extent of the GCP is limited to a smaller horizontal area during the 6 April 201631 May 2016 time period compared to the 2004-16 time average (Fig. 1), consistent with topographic upwelling of a weaker-than-average EUC. On seasonal time scales, Kessler et al. (1998) and Kessler (2006) show that meridional and zonal wind stresses along the equator between $95^{\circ}$ and $90^{\circ} \mathrm{W}$ are at a minimum during April-May (consistent with Fig. 2), while equatorial SST is at a maximum. Climatologically, the EUC is seasonally stronger than average during April-May (Johnson et al. 2002), yet the EUC observed by the gliders during April-May 2016 is weaker than average.
This is likely an impact of the end of the 2015/16 El Niño.

(iii) The end of the strong 2015/16 El Niño may have resulted in decreased equatorial upwelling compared to a long-term average. In addition to potentially decreasing the maximum velocity of the EUC core, El Niño events are associated with a decrease or reversal in easterly trade winds after initial anomalous westerly wind bursts (Firing et al. 1983). A decrease in trade wind magnitude could result in minimal surface divergence along the equator and decreased equatorial upwelling, in addition to decreasing potential wind-driven topographic upwelling in the lee of the Galápagos Archipelago (Fig. 2).

Regional ocean model results of Karnauskas et al. (2007) indicate upwelling in the upper $300 \mathrm{~m}$ along the equator west of the Galápagos Archipelago, with a maximum near $300 \mathrm{~m}$ (Karnauskas et al. 2007, their Fig. 12d). On the equator, upwelling is apparent over the entire upper $300 \mathrm{~m}$ and over the distance between $93 \mathrm{~W}$ and the archipelago, consistent with the meridional divergence of Fig. 7a. If we integrate only the meridional divergence from the surface to obtain an estimate for vertical velocity, the maximum vertical velocity is near $300 \mathrm{~m}$ with a magnitude twice that seen in Fig. 9c. While this estimate assumes that $\partial u / \partial x$ is zero, it is likely that $\partial u / \partial x$ is negative as the EUC reaches the archipelago, which would reduce the resulting vertical velocity. The maximum in vertical velocity near $300 \mathrm{~m}$ in Fig. 9c is consistent with the meridional velocity section of Fig. 7a.

The same model (Karnauskas et al. 2007, their Fig. 14) shows deepening and slowing of the two branches of the EUC as they bifurcate around the archipelago. It remains to examine the mechanisms resulting in vertical spreading of the EUC after bifurcation. It would also be useful to obtain measurements of temperature, salinity, and current velocity along a zonal transect between $93 \mathrm{~W}$ and the archipelago at the latitude of minimum SST within the region of the GCP and to directly compare the observed zonal transect with model estimates of isopycnal shoaling/deepening. This approach would have the benefit of examining whether cold SST of the GCP is due to isopycnal shoaling, vertical mixing, or a combination of these.

\section{2) Potential ERror SOURCES}

We identify three main potential sources of error in the vertical velocity calculation:

(i) The assumption of zero divergence at 10-m depth: Easterly wind stress along the equator (Fig. 2b) 
would result in nonzero Ekman divergence above $10 \mathrm{~m}$. The gliders' downward looking AD2CPs do not resolve depth-dependent velocity shallower than $10 \mathrm{~m}$ so any divergence in the upper $10 \mathrm{~m}$ is not included in our analysis. Such a divergence would shift the entire vertical velocity profile toward more positive values, increasing upwelling estimates due to integrating the net horizontal transport profile without impacting estimated errors. During AprilMay 2016, winds were light over the GCP (Fig. 2b), suggesting that wind-driven surface divergence was small. Winds in this region during the study period are expected to be weak compared to the annual mean (Fig. 2a), since the April-May time period corresponds to the seasonal trade wind minimum (Kessler et al. 1998; Kessler 2006).

(ii) Unresolved flow near the boundary with the Galápagos Archipelago: The ND and SD lines terminate approximately $5 \mathrm{~km}$ from the archipelago, leaving a region of unresolved flow. A reversal of flow (into $V_{\mathrm{gl}}$ ) in these boundary regions would decrease vertical velocity. If this flow reversal had an average magnitude of $1 \mathrm{~m} \mathrm{~s}^{-1}$ over 5-km-wide by 300-m-deep regions on both sides of Isla Isabela, the resulting transport would be $3 \mathrm{~Sv}$ into the volume, which is not sufficient to reduce the total transport of $-3.6 \pm 0.7 \mathrm{~Sv}$ to zero. It is unlikely that there is such a strong reversal of flow into $V_{\mathrm{gl}}$ within the unresolved boundary regions that vertical velocity would be near zero at 300-m depth.

(iii) Unresolved temporal variability: Velocity changes that occur during the time it takes a glider to complete a section are not fully resolved. Highfrequency motions with periods less than one day are filtered via Eq. (2), but processes with time scales close to the 10-20-day time scales required for gliders to occupy individual transects have the potential to impact the vertical velocity estimate.

As a simple check of the estimated vertical velocity profile in the upper $50 \mathrm{~m}$, we consider the minimum SST in Fig. $1 \mathrm{c}$ of $22^{\circ} \mathrm{C}$, which occurs at a latitude of $0.75^{\circ} \mathrm{S}$. Along $93 \mathrm{~W}$ at the same latitude, the average depth of the $22^{\circ} \mathrm{C}$ isotherm is approximately $20 \mathrm{~m}$. The distance of the point of minimum SST in the GCP from $93 \mathrm{~W}$ is approximately $130 \mathrm{~km}$, which suggests that a parcel of water with minimum SST in the GCP rises $20 \mathrm{~m}$ over $130 \mathrm{~km}$ between $93 \mathrm{~W}$ and the point at which it reaches the surface. If we assume the parcel travels at a constant velocity equal to the velocity it has when crossing $93 \mathrm{~W}$ (approximately $0.1 \mathrm{~m} \mathrm{~s}^{-1}$ at $20-\mathrm{m}$ depth and $0.75^{\circ} \mathrm{S}$, Fig. 6a), the vertical velocity necessary to reach the surface by the time it reaches the GCP is $1.3 \mathrm{~m} \mathrm{day}^{-1}$.
This estimate is remarkably close to that of the average vertical velocity profile in the upper $50 \mathrm{~m}$, which has a maximum value of $1.5 \mathrm{~m} \mathrm{day}^{-1}$ at $25-\mathrm{m}$ depth.

\section{3) Mechanisms}

Upwelling near the surface coincides with strengthening of the SEC between ND and 93W and may be due to poleward Ekman transport combined with shoaling of some EUC flow between $93 \mathrm{~W}$ and the diagonals. Increase in SEC transport may be attributed to entrainment of both upwelled waters and the northern branch of the split EUC. However, entrainment of the EUC into the SEC or vice versa alone is not sufficient to explain divergence near the surface, since $\triangle E U C$ and $\triangle$ SEC are both negative (section $3 b$ ).

Upwelling below $110 \mathrm{~m}$ is partially associated with vertical spreading of the EUC across ND and SD compared to the coherent EUC core across $93 \mathrm{~W}$, resulting in net divergence below the EUC core. In layers I ( $0-35 \mathrm{~m})$ and III (75-225 m) of section 3b, negative transport has greater magnitude than positive transport associated with the EUC. This suggests that a mechanism beyond vertical spreading of the EUC is necessary to account for the overall net divergence (upwelling) in the upper $300 \mathrm{~m}$. During the 2-month average presented here and a 3-yr average also calculated using ROGER observations (not shown), divergence in the along-track direction $(\partial v / \partial y)$ along $93 \mathrm{~W}$ extends throughout the upper $300 \mathrm{~m}$ (Fig. 7a, 2-month average). It is possible that, in an incompressible ocean, meridional divergence along $93 \mathrm{~W}$ is balanced by a zonal convergence, such as a slowing EUC as it moves eastward. While the normal velocities of Fig. 6 indicate that the EUC is slowing between $93 \mathrm{~W}$ and the Galápagos Archipelago, the EUC is confined to the upper $150 \mathrm{~m}$ and meridional divergence occurs over the entire upper $300 \mathrm{~m}$. Combined with overall net divergence in the upper $300 \mathrm{~m}$, it is likely that the meridional divergence along 93W (Fig. 7a) is associated with upwelling just north of the equator. The average vertical velocity profile of Fig. 9c may be a result of horizontal divergence and convergence associated with the EUC and SEC passing the Galápagos, superimposed on upwelling in the upper $300 \mathrm{~m}$ that is suggested by the meridional velocity section along $93 \mathrm{~W}$. The mechanism driving this meridional divergence is currently unknown.

Vertical spreading of the EUC as it bifurcates around the Galápagos (Fig. 6) implies downwelling, not the inferred upwelling below $75 \mathrm{~m}$ (Fig. 9c). Average SST (Fig. 1c) reaches a minimum in a limited region near $0.75^{\circ} \mathrm{S}$, consistent with the chlorophyll (ocean color) observations of Palacios (2004). According to average density sections (black contours of Fig. 11), isopycnals 
slope downward between 93W and SD (and presumably between $93 \mathrm{~W}$ and ND, although density estimates are not available). We expect isopycnals to slope upward between 93W and the Galápagos Archipelago near the latitude of minimum SST (maximum upwelling), which the gliders did not directly observe. In addition, SST is impacted by wind stress and anomalously cold SST resulting from upwelling is likely advected into a broader region than where the upwelling actually occurs. While sections of velocity normal to $93 \mathrm{~W}$ and SD indicate downwelling as the EUC flows eastward, SST (Fig. 1c) suggests a limited region of localized, intense upwelling within $A_{\mathrm{gl}}$ that was not directly observed due to the positions of the glider transects outside of the region of minimum SST. The average vertical velocity profile over $A_{\mathrm{gl}}$ thus incorporates intense upwelling just off the coast of Isla Isabela, possible upwelling associated with the meridional divergence over the upper $300 \mathrm{~m}$, and possible regions of downwelling consistent with vertical spreading of the two branches of the EUC (Fig. 14).

\section{Summary}

Autonomous underwater glider observations during April-May 2016 capture the bifurcation of the EUC around the Galápagos Archipelago (Fig. 6) and allow estimation of upwelling (Fig. 9) that supports the persistent, anomalously cold SST of the GCP (Fig. 1). Time-average velocity over the 52-day time period shows a coherent EUC and SEC along 93W. Along both $\mathrm{ND}$ and $\mathrm{SD}$, there is transport out of $V_{\mathrm{g} 1}$ at the depth of the EUC, indicating the EUC splits into northern and southern branches as it encounters the Galápagos Archipelago (Fig. 14). The existence of the GCP may be explained by a combination of topographic upwelling of the EUC as it reaches the Galápagos Archipelago, wind-driven coastal upwelling, and Ekman divergence along the equator. Surface $(10 \mathrm{~m})$ winds in the vicinity of the GCP are light compared to those near $140^{\circ} \mathrm{W}$ (Fig. 2), yet the GCP is characterized by temperatures colder than those associated with general equatorial upwelling across the central Pacific (Fig. 1c). An additional mechanism is needed, supporting topographic upwelling as a mechanism behind the GCP.

Although this study was limited in time to a single 52-day period in 2016, we successfully observed the path of the EUC just west of the Galápagos Archipelago. Future studies will leverage temporal variability over the full 3-yr time period of available glider observations to further understand mechanisms behind results presented here. Results of this

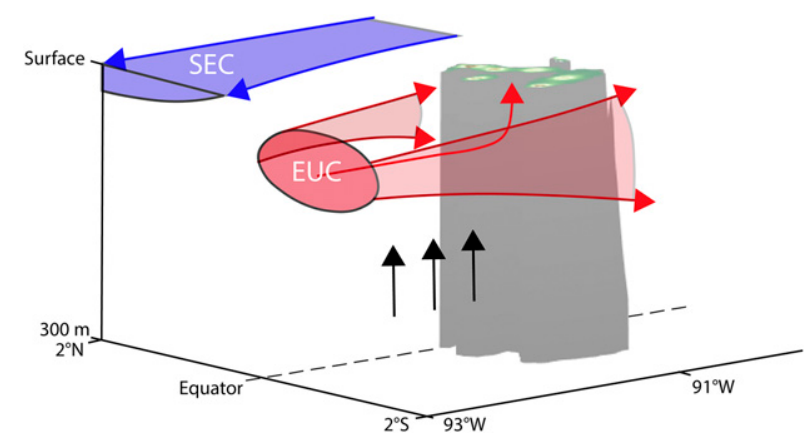

FIG. 14. Schematic of upwelling and the bifurcation of the EUC in the region west of the Galápagos Archipelago. Eastward, EUC-related flow is shown in red; splitting of the EUC into a north and south branch around the archipelago and upwelling of the EUC near Isla Isabela are indicated by red arrows. Vertical black arrows indicate upwelling consistent with meridional divergence over the upper $300 \mathrm{~m}$. Westward SEC flow is shown in blue.

study will be quantitatively compared to model results (e.g., Karnauskas et al. 2007, 2014) to improve understanding of implications of the observed bifurcation and upwelling of the EUC at the Galápagos Archipelago.

Acknowledgments. Spray glider operations would not have been successful without the support of the Instrument Development Group at the Scripps Institution of Oceanography (Jeff Sherman, Evan Randall-Goodwin, Derek Vana, Kyle Grindley, Brent Jones, and Ben Reineman) and Larry George and Patrick Deane at WHOI. Glider deployment was made possible through collaboration with the Ecuadorian Instituto Oceanográfico de la Armada (INOCAR). We thank Dr. William Kessler and an anonymous reviewer for their comments and suggestions. This work was supported by National Science Foundation (Grants OCE-1232971 and OCE1233282) and the NASA Earth and Space Science Fellowship Program (Grant 80NSSC17K0443).

Data availability statement: Spray glider observations from ROGER are available from http://spraydata.ucsd. edu and should be cited using the following DOI: 10.21238/S8SPRAY0090 (Rudnick et al. 2020). Wind data used were from the E.U. Copernicus Marine Environment Monitoring Service (CMEMS), product WIND_GLO_WIND_L4_REP_OBSERVATIONS 012_003. The Group for High Resolution Sea Surface Temperature (GHRSST) Multi-scale Ultra-high Resolution SST data were obtained from the NASA EOSDIS Physical Oceanography Distributed Active Archive Center (PO.DAAC) at the Jet Propulsion Laboratory, Pasadena, CA (http://dx.doi.org/10.5067/GHGMR-4FJ01). Color maps are provided by Thyng et al. (2016). 
(a)

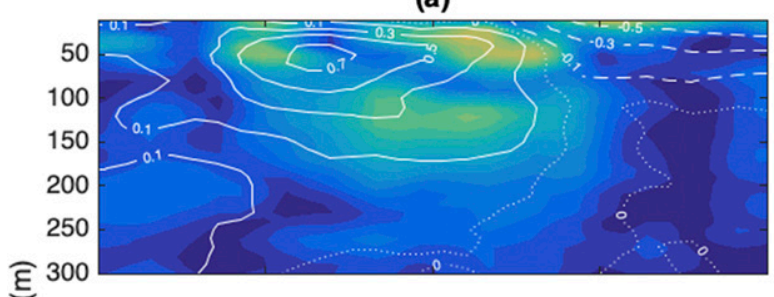

(b)

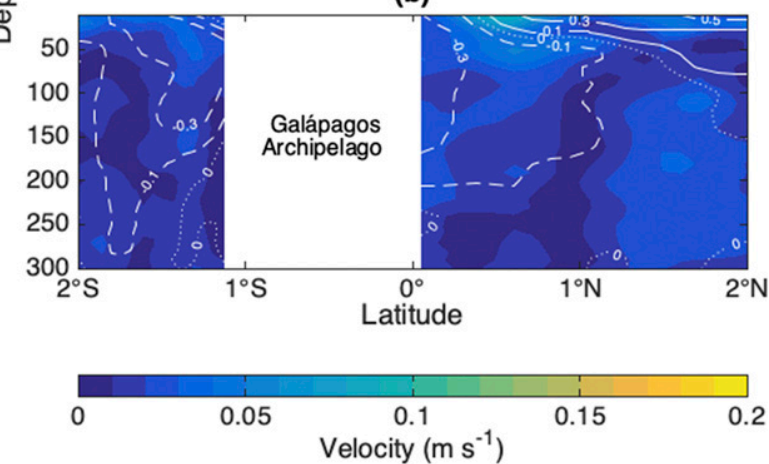

FIG. A1. Estimated standard error of time average velocity normal to (a) $93 \mathrm{~W}$ and (b) ND and SD. Contours of normal velocity $\left(\mathrm{m} \mathrm{s}^{-1}\right.$ ) are shown in white; negative velocity contours are dashed.

\section{APPENDIX}

\section{Standard Error of Average Sections}

Standard error of average velocity (Fig. A1) and salinity (Fig. A2) are estimated as

\section{(a)}

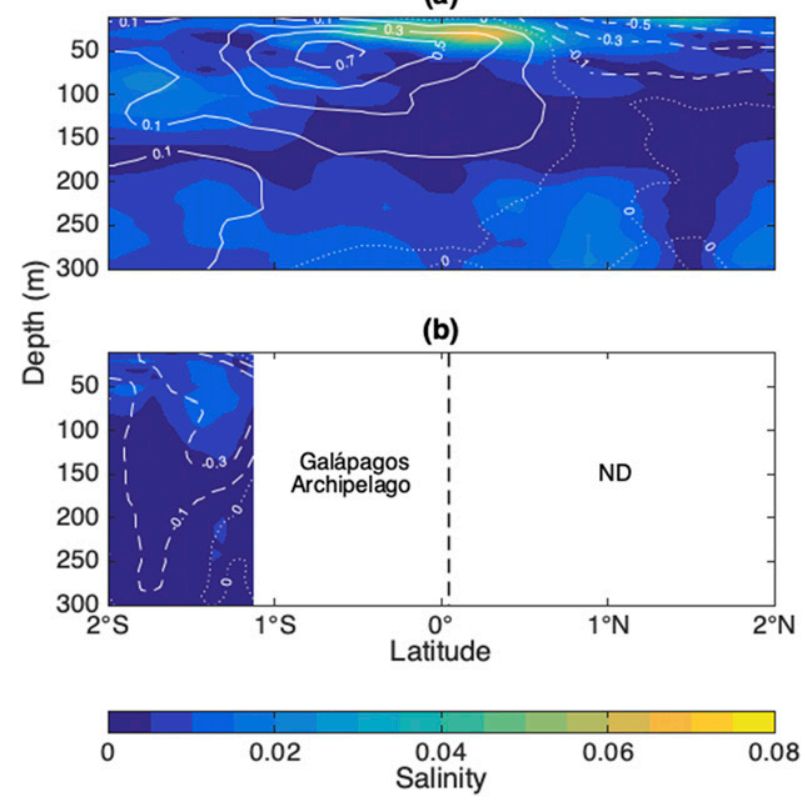

FIG. A2. As in Fig. A1, but for salinity.

$$
\sigma_{e}(y, z)=\frac{\sqrt{\sum_{n=1}^{N}[C(y, z)-\overline{C(y, z)}]^{2}}}{N},
$$

where $C(y, z)$ is velocity or salinity of a point on a gridded transect, and $y$ is along-line distance.

\section{REFERENCES}

Bentamy, A., and D. C. Fillon, 2012: Gridded surface wind fields from Metop/ASCAT measurements. Int. J. Remote Sens., 33, 1729-1754, https://doi.org/10.1080/01431161.2011. 600348.

Bjerknes, J., 1969: Atmospheric teleconnections from the equatorial Pacific. Mon. Wea. Rev., 97, 163-172, https://doi.org/ 10.1175/1520-0493(1969)097<0163:ATFTEP >2.3.CO;2.

Charney, J. G., 1959: Non-linear theory of a wind-driven homogeneous layer near the equator. Deep-Sea Res., 6, 303-310, https://doi.org/10.1016/0146-6313(59)90089-9.

— currents in homogeneous oceans. J. Phys. Oceanogr., 1, 149-160, https://doi.org/10.1175/1520-0485(1971)001<0149: SOWDEC $>2.0 . \mathrm{CO} ; 2$.

Cromwell, T., R. B. Montgomery, and E. D. Stroup, 1954: Equatorial undercurrent in Pacific Ocean revealed by new methods. Science, 119, 648-649, https://doi.org/10.1126/ SCIENCE.119.3097.648.

Fiedler, P. C., and L. D. Talley, 2006: Hydrography of the eastern tropical Pacific: A review. Prog. Oceanogr., 69, 143-180, https://doi.org/10.1016/J.POCEAN.2006.03.008.

Firing, E., R. Lukas, J. Sadler, and K. Wyrtki, 1983: Equatorial undercurrent disappears during 1982-1983 El Niño. Science, 222, 1121-1123, https://doi.org/10.1126/SCIENCE.222.4628. 1121.

Hayes, S. P., L. J. Mangum, J. Picaut, A. Sumi, and K. Takeuchi, 1991: TOGA-TAO: A moored array for real-time measurements in the tropical Pacific Ocean. Bull. Amer. Meteor. Soc., 72, 339-347, https://doi.org/10.1175/1520-0477(1991)072<0339: TTAMAF $>2.0 . \mathrm{CO} ; 2$

Houvenaghel, G. T., 1978: Oceanographic conditions in the Galapagos archipelago and their relationship with life on the islands. Upwelling Ecosystems, R. Boje and M. Tomczak, Eds., Springer, 181-200.

Johnson, E. S., and D. S. Luther, 1994: Mean zonal momentum balance in the upper and central equatorial Pacific Ocean. J. Geophys. Res., 99, 7689-7705, https://doi.org/10.1029/ 94JC00033.

Johnson, G. C., and M. J. McPhaden, 1999: Interior pycnocline flow from the subtropical to the equatorial Pacific Ocean. J. Phys. Oceanogr., 29, 3073-3089, https://doi.org/10.1175/ 1520-0485(1999)029<3073:IPFFTS $>2.0$.CO;2.

,-- , G. D. Rowe, and K. E. McTaggart, 2000: Upper equatorial Pacific Ocean current and salinity variability during the 1996-1998 El Niño-La Niña cycle. J. Geophys. Res., 105, 1037-1053, https://doi.org/10.1029/1999JC900280.

— $-\ldots$, and E. Firing, 2001: Equatorial Pacific Ocean horizontal velocity, divergence, and upwelling. J. Phys. Oceanogr., 31, 839-849, https://doi.org/10.1175/1520-0485(2001)031<0839: EPOHVD>2.0.CO;2.

—, B. M. Sloyan, W. S. Kessler, and K. E. McTaggart, 2002: Direct measurements of upper ocean currents and water properties 
across the tropical Pacific during the 1990s. Prog. Oceanogr., 52, 31-61, https://doi.org/10.1016/S0079-6611(02)00021-6.

Karnauskas, K. B., R. Murtugudde, and A. J. Busalacchi, 2007: The effect of the Galápagos Islands on the equatorial Pacific cold tongue. J. Phys. Oceanogr., 37, 1266-1281, https://doi.org/ 10.1175/JPO3048.1.

, — - and — 2008: The effect of the Galápagos Islands on ENSO in forced ocean and hybrid coupled models. J. Phys. Oceanogr., 38, 2519-2534, https://doi.org/10.1175/ 2008JPO3848.1.

,-- , and -2010 : Observing the Galápagos-EUC interaction: Insights and challenges. J. Phys. Oceanogr., 40, 27682777, https://doi.org/10.1175/2010JPO4461.1.

,-- , and W. B. Owens, 2014: Climate and the global reach of the Galápagos archipelago. The Galápagos: A Natural Laboratory for the Earth Sciences, Geophys. Monogr., Vol. 204, Amer. Geophys. Union, 215-231.

- S. Jenouvrier, C. W. Brown, and R. Murtugudde, 2015: Strong sea surface cooling in the eastern equatorial Pacific and implications for Galapagos Penguin conservation. Geophys. Res. Lett., 42, 6432-6437, https://doi.org/10.1002/ 2015 GL064456.

Kessler, W. S., 2006: The circulation of the eastern tropical Pacific: A review. Prog. Oceanogr., 69, 181-217, https://doi.org/10.1016/ J.POCEAN.2006.03.009.

— L. M. Rothstein, and D. Chen, 1998: The annual cycle of SST in the eastern tropical Pacific, diagnosed in an ocean GCM. J. Climate, 11, 777-799, https://doi.org/10.1175/15200442(1998)011<0777:TACOSI >2.0.CO;2.

Knauss, J. A., 1966: Further measurements and observations of the Cromwell Current. J. Mar. Res., 24, 205-240.

Lau, K. M., and S. Yang, 2015: Tropical meteorology and climate | Walker circulation. Encyclopedia of Atmospheric Sciences, 2nd ed. G. North, J. Pyle and F. Zhang, Eds., Academic Press, 177-181.

Liu, Y., L. Xie, J. M. Morrison, D. Kamykowski, and W. V. Sweet, 2014: Ocean circulation and water mass characteristics around the Galápagos archipelago simulated by a multiscale nested ocean circulation model. Int. J. Oceanogr., 2014, 1-16, https:// doi.org/10.1155/2014/198686.

Lukas, R., 1986: The termination of the equatorial undercurrent in the eastern Pacific. Prog. Oceanogr., 16, 63-90, https://doi.org/ 10.1016/0079-6611(86)90007-8.

- , and E. Firing, 1984: The geostrophic balance of the Pacific equatorial undercurrent. Deep-Sea Res., 31A, 61-66, https:// doi.org/10.1016/0198-0149(84)90072-4.

McCreary, J., and P. Lu, 1994: Interaction between the subtropical and equatorial ocean circulations: The subtropical cell. J. Phys. Oceanogr., 24, 466-497, https://doi.org/10.1175/1520-0485(1994) 024<0466:IBTSAE $>2.0$. CO;2.

Meinen, C. S., M. J. McPhaden, G. C. Johnson, C. S. Meinen, M. J. McPhaden, and G. C. Johnson, 2001: Vertical velocities and transports in the equatorial Pacific during 1993-99. J. Phys. Oceanogr., 31, 3230-3248, https://doi.org/10.1175/ 1520-0485(2001)031<3230:VVATIT > 2.0.CO;2.

Mitchell, T. P., and J. M. Wallace, 1992: The annual cycle in equatorial convection and sea surface temperature. J. Climate, 5, 1140-1156, https://doi.org/10.1175/1520-0442(1992)005<1140: TACIEC $>2.0 . C O ; 2$.

National Centers for Environmental Information, 2016: Documentation for The Group for High Resolution Sea Surface Temperature (GHRSST) data archived at NCEI (NCEI Accession 0123222). Version 2.2, https://catalog.data.gov/ dataset/documentation-for-the-group-for-high-resolution-seasurface-temperature-ghrsst-data-archived-at.

Palacios, D. M., 2004: Seasonal patterns of sea-surface temperature and ocean color around the Galápagos: Regional and local influences. Deep-Sea Res. II, 51, 43-57, https://doi.org/10.1016/ J.DSR2.2003.08.001.

Pedlosky, J., 1987: An inertial theory of the equatorial undercurrent. J. Phys. Oceanogr., 17, 1978-1985, https://doi.org/10.1175/ 1520-0485(1987)017<1978:AITOTE > 2.0.CO;2.

Perez, R. C., and W. S. Kessler, 2009: Three-dimensional structure of tropical cells in the central equatorial Pacific Ocean. J. Phys. Oceanogr., 39, 27-49, https://doi.org/10.1175/ 2008JPO4029.1.

Philander, S. G. H., 1973: Equatorial undercurrent: Measurements and theories. Rev. Geophys., 11, 513, https://doi.org/10.1029/ RG011I003P00513.

Qiao, L., and R. H. Weisberg, 1997: The zonal momentum balance of the equatorial undercurrent in the central Pacific. J. Phys. Oceanogr., 27, 1094-1119, https://doi.org/10.1175/ 1520-0485(1997)027<1094:TZMBOT>2.0.CO;2.

Reynolds, R. W., T. M. Smith, C. Liu, D. B. Chelton, K. S. Casey, and M. G. Schlax, 2007: Daily high-resolution-blended analyses for sea surface temperature. J. Climate, 20, 5473-5496, https://doi.org/10.1175/2007JCLI1824.1.

Roundy, P. E., and G. N. Kiladis, 2006: Observed relationships between oceanic Kelvin waves and atmospheric forcing. J. Climate, 19, 5253-5272, https://doi.org/10.1175/ JCLI3893.1.

Rudnick, D. L., and S. T. Cole, 2011: On sampling the ocean using underwater gliders. J. Geophys. Res., 116, C08010, https:// doi.org/10.1029/2010JC006849.

_ R. E. Davis, and J. T. Sherman, 2016: Spray underwater glider operations. J. Atmos. Oceanic Technol., 33, 1113-1122, https:// doi.org/10.1175/JTECH-D-15-0252.1.

_ , K. D. Zaba, R. E. Todd, and R. E. Davis, 2017: A climatology of the California Current System from a network of underwater gliders. Prog. Oceanogr., 154, 64-106, https://doi.org/ 10.1016/J.POCEAN.2017.03.002.

__ J. T. Sherman, and A. P. Wu, 2018: Depth-average velocity from Spray underwater gliders. J. Atmos. Oceanic Technol., 35, 1665-1673, https://doi.org/10.1175/JTECHD-17-0200.1.

- - W. B. Owens, K. B. Karnauskas, and T. M. S. Johnston, 2020: Repeat observations by gliders in the equatorial region. Scripps Institution of Oceanography, Instrument Development Group, accessed 9 March 2020, https://doi.org/ 10.21238/S8SPRAY0090.

Sherman, J., R. E. Davis, W. B. Owens, and J. Valdes, 2001: The autonomous underwater glider "Spray". IEEE J. Oceanic Eng., 26, 437-446, https://doi.org/10.1109/48.972076.

Sweet, W. V., J. M. Morrison, D. Kamykowski, B. A. Schaeffer, S. Banks, and A. McCulloch, 2007: Water mass seasonal variability in the Galápagos archipelago. Deep-Sea Res. I, 54, 2023-2035, https://doi.org/10.1016/J.DSR.2007.09.009.

Thyng, K., C. Greene, R. Hetland, H. Zimmerle, and S. DiMarco, 2016: True colors of oceanography: Guidelines for effective and accurate colormap selection. Oceanography, 29, 9-13, https://doi.org/10.5670/OCEANOG.2016.66.

Todd, R. E., D. L. Rudnick, J. Sherman, W. B. Owens, and L. George, 2017: Absolute velocity estimates from autonomous underwater gliders equipped with Doppler current profilers. J. Atmos. Oceanic Technol., 34, 309-333, https:// doi.org/10.1175/JTECH-D-16-0156.1. 
Visbeck, M., 2002: Deep velocity profiling using lowered acoustic Doppler current profilers: Bottom track and inverse solutions. J. Atmos. Oceanic Technol., 19, 794-807, https://doi.org/ 10.1175/1520-0426(2002)019<0794:DVPULA > 2.0.CO;2.

Weisberg, R. H., and L. Qiao, 2000: Equatorial upwelling in the central Pacific estimated from moored velocity profilers. J. Phys. Oceanogr., 30, 105-124, https://doi.org/10.1175/15200485(2000)030<0105:EUITCP $>2.0$. CO;2.

Wyrtki, K., 1966: Oceanography of the eastern equatorial Pacific Ocean. Oceanogr. Mar. Biol. Annu. Rev., 4, 33-68.
- 1981: An estimate of equatorial upwelling in the Pacific. J. Phys. Oceanogr., 11, 1205-1214, https://doi.org/10.1175/ 1520-0485(1981)011<1205:AEOEUI>2.0.CO;2.

- and G. Meyers, 1977: Variability of the thermal structure in the central equatorial Pacific Ocean. Tech. Rep. HIG-77-1, University of Hawai'i at Mānoa, Honolulu, HI, 75 pp.

- , and B. Kilonsky, 1984: Mean water and current structure during the Hawaii-to-Tahiti shuttle experiment. J. Phys. Oceanogr., 14, 242-254, https://doi.org/10.1175/1520-0485(1984) 014<0242:MWACSD>2.0.CO;2. 